\title{
A comprehensive insight into the molecular and cellular mechanisms of the effects of Propolis on preserving renal function: a systematic review
}

Paniz Anvarifard ${ }^{1}$, Maryam Anbari ${ }^{1}$, Alireza Ostadrahimi i, ${ }^{2,3}$, Mohammadreza Ardalan $^{4}$ and Zohreh Ghoreishi ${ }^{2,3^{*}}$ (1)

\begin{abstract}
Background: The present systematic review is conducted, focusing on the existing evidence of Propolis's effects due to its various health benefits, mainly antioxidant and anti-inflammatory properties on preserving renal function.

Methods: A systematic search of PubMed, Scopus, Embase, ProQuest, and Google Scholar was undertaken for relevant papers published from the start until January 2021.

Results: This review revealed that Propolis affects fasting blood sugar (FBS), postprandial blood glucose, advanced glycation end products (AGEs) concentrations, malondialdehyde (MDA) levels, urinary concentrations of reactive oxygen metabolites (Tbars), total oxidant status (TOS), oxidative stress index (OSI), and 8-hydroxy-2'-deoxyguanosine $(8-\mathrm{OHdG})$ formation favorably. The findings on hemoglobin $\mathrm{A} 1 \mathrm{C}(\mathrm{HbA1C})$, insulin, homeostasis model assessment of insulin resistance (HOMA-IR), $\beta$-cell function (HOMA- $\beta$ ), quantitative insulin sensitivity check index (QUICKI), and lipid profile were controversial. Moreover, a significant reduction in renal nuclear factor kappa B (NF-kB), serum immunoglobulins, renal ED-1+ ${ }^{+}$cells, and urinary monocyte chemoattractant protein-1 (MCP-1) following Propolis supplementation has been reported, while the results on interleukin-6 (IL-6), tumor necrosis factor a (TNF-a), nitric oxide (NO), nitric oxide synthetase (NOS), and high sensitivity C-reactive protein (hs-CRP) were controversial. Furthermore, included studies showed its anti- proteinuria and kidney restoring effects.
\end{abstract}

Conclusion: In this review, both human and animal studies provide us evidences that Propolis could potentially improve the glycemic status, oxidative stress, renal tissue damage, and renal function. Further studies are needed to determine the underlying mechanisms.

Keywords: Propolis, Acute kidney injury, AKI, Chronic kidney disease, CKD, Renal function, Kidney disease, Systematic review

\section{Introduction}

Kidney disease is a serious global health challenge with a growing prevalence $[1,2]$ and chronologically is divided into two main categories, acute kidney injury (AKI) and

\footnotetext{
*Correspondence: ghoreyshiz@tbzmed.ac.ir

${ }^{2}$ Nutrition Research Center, Tabriz University of Medical Sciences, Tabriz, Iran

Full list of author information is available at the end of the article
}

chronic kidney disease (CKD) [1]. AKI affected 10-20\% of hospitalized adults and up to $60 \%$ of critically ill patients worldwide in 2015 [2, 3]. The current diagnostic approach of AKI, is based on an acute decrease of glomerular filtration rate (GFR), reflected by an acute rise in serum creatinine (SCr) levels and/or a decline in urine output over a given time interval. The leading causes of AKI are hospital-acquired (renal ischemia, sepsis, and original author(s) and the source, provide a link to the Creative Commons licence, and indicate if changes were made. The images or other third party material in this article are included in the article's Creative Commons licence, unless indicated otherwise in a credit line to the material. If material is not included in the article's Creative Commons licence and your intended use is not permitted by statutory regulation or exceeds the permitted use, you will need to obtain permission directly from the copyright holder. To view a copy of this licence, visit http://creativecommons.org/licenses/by/4.0/. The Creative Commons Public Domain Dedication waiver (http://creativeco mmons.org/publicdomain/zero/1.0/) applies to the data made available in this article, unless otherwise stated in a credit line to the data. 
nephrotoxic drugs or herbals) and community-acquired (such as infections, diarrhea, and dehydration) diseases [3]. On the other hand, the global prevalence of CKD in 2015 was $11-13 \%$, with the majority of stage 3 , in non-hospitalized adults $[2,4]$. According to the current guidelines, CKD is defined by gradual and permanent decreased renal function (GFR) and/or presence of kidney damage (based on imaging or proteinuria) for more than 3 months, irrespective of the underlying cause [2, 4, 5]. The major causes of CKD are diabetes mellitus (DM), hypertension (HTN), infections, genetic diseases (such as polycystic kidney disease), and autoimmune diseases (such as immunoglobulin A glomerulonephritis and lupus) $[1,5]$. Diabetic kidney disease (DKD) is a kind of CKD that occurs in diabetic patients, clinically defined as diabetic nephropathy (DN) (the presence of albuminuria, impaired GFR $\left(<60 \mathrm{~mL} / \mathrm{min} / 1.73 \mathrm{~m}^{2}\right)$, or both) encompasses with atheroembolic disease, ischemic nephropathy, and interstitial fibrosis [6-8].

Kidney disease, as a silent killer, leads to various health complications, including frailty, hospitalization, cognitive dysfunction, reduced quality of life, end-stage renal disease (ESRD), cardiovascular disease (CVD) as the leading cause of death in the world, and premature mortality $[2,4-6,9,10]$. Therefore, the prevention and early detection and treatment of kidney disease can be a practical approach for the global decline in ESRD, CVD, and total mortality $[2,5]$. Based on the present evidence, it seems that hyperglycemia, dyslipidemia, oxidative stress (OS), and inflammation are four critical parameters for AKI and CKD pathogenesis; indeed, they are considered as causes and/or consequences of kidney disease $[1,11,12]$.

Although various medications are available in the market to control and reduce kidney disease complications, new remedies with more therapeutic benefits and less toxicity still are needed [13]. Nowadays, natural products have been highly considered for their role in alleviating OS and inflammation, which might prevent kidney disease progression, as well as complications' reduction also [10,13]. Propolis, due to its polyphenolic content, multi-targeted effectiveness, and low toxicity is a good candidate [14]. Honeybees make Propolis by mixing their saliva containing specific enzymes and beeswax with exudate collected from plants, and it contains multiple polyphenolic compounds, mostly flavonoids and phenolic acids $[14,15]$. Propolis has widely used to treat various diseases due to its antimicrobial, antiseptic, antiulcer, anti-cavity, anti-inflammatory, antioxidant, anticancer, antihypertensive, antiplatelet, and immunomodulatory properties [14, 16-18]. Notably, Propolis may lower the development of neurodegenerative disorders, cancer, diabetes, liver and kidney injuries, immune diseases, and cardiovascular events through its antioxidant properties.
It is also supposed that Propolis may attenuate the adverse effects of chemotherapeutic agents $[15,16]$. Clinical studies in both mice and humans show that Propolis and its compounds are usually well-tolerated and are non-toxic if used in moderation [14].

Despite the number of studies that investigated the effects of Propolis on metabolic indices such as glycemic status, lipid profile, OS, inflammation, as well as renal function in kidney disease [10,13, 19-33], there is no comprehensive assessment of the existing evidence based on our review. Therefore, the purpose of this systematic review was to summarize the available data and compare the results of the human and animal studies on the effects of Propolis on metabolic status and renal function.

\section{Material and methods}

\section{Search strategy}

To identify the eligible studies for this systematic review, a search of PubMed, Scopus, Embase, ISI Web of Science, ProQuest, and Google Scholar online databases was conducted from the start up to January 2021, using the key words ("Propolis" [MeSH Terms] OR "Propolis" [Title/Abstract] OR "Bee glue" [Title/Abstract] OR "Bee bread" [Title/Abstract] or "Honeybee" [Title/Abstract] OR "Chrysin" [Title/Abstract]) AND ("kidney" [MeSH Terms] OR "kidney" [Title/Abstract] OR "renal" [MeSH Terms] OR "renal" [Title/Abstract] OR "nephropathy" [Title/Abstract] OR "glomerular filtration rate" [Title/ Abstract] OR "GFR" [Title/Abstract] OR "Albuminuria" [MeSH Terms] OR "Albuminuria" [Title/Abstract] or "Microalbuminuria" [Title/Abstract] OR "Macroalbuminuria" [Title/Abstract] OR "Proteinuria" [Title/Abstract] OR "Creatinine" [Title/Abstract] OR "dialysis" [MeSH Terms] OR "dialysis" [Title/Abstract] OR "Haemodialysis" [Title/Abstract] OR "Catheter-related bloodstream infections" [Title/Abstract] OR "Central venous catheters" [Title/Abstract]). The search was restricted to clinical trials and animal studies published only in the English language. Guideline of the Preferred Reporting Items for Systematic Reviews and Meta-Analyses (PRISMA) was used for designing and reporting this systematic review (see Additional file 1).

\section{Inclusion and exclusion criteria}

After removing the repeated articles, the titles and abstracts of all imported studies were screened by two independent researchers (P. A. and M. A.). Studies were eligible for inclusion if they meet the following criteria: (1) clinical trial or animal study, (2) publishing in English language, and (3) evaluating Propolis administration effect on kidney disease (only AKI or CKD). Studies were excluded if they 1) were reviews, conference papers, observational studies, or abstracts only, 
(2) used in-vitro models, (3) investigated other kinds of kidney disease (such as sepsis-related kidney disease or medication-induced kidney toxicity), (4) used some specific compound of Propolis (such as chrysin), and 5) were published in a non-English language.

\section{Selection, extraction, and assessment of study quality}

Two investigators (P. A. and M. A.) screened titles and abstracts of all imported studies to identify articles requiring full-text review using a standardized checklist of the research question and inclusion and exclusion criteria. Any disagreements between the researchers were resolved through consensus. Then, the quality of the included articles was checked by the third investigator (Z. G.). Finally, the following variables were extracted from included studies into a standardized template: first author's name, publication date, study location, type of study, cause of kidney disease, samples characteristics (gender, weight, age, sample size, and groups' allocation), study design, daily dose, duration, and route of Propolis administration, and the main results.

\section{Results}

\section{Selected articles}

The flowchart of the process for selecting the studies was summarized in Fig. 1. A total number of 1202 articles were retrieved after the initial search, 541 were duplicated, and therefore 661 non-duplicated publications remained. Of these, 631 articles were excluded after checking titles and abstracts. In the next step, 13 articles were excluded due to not meeting the eligibility criteria. Finally, only 17 articles met the selection criteria and were included in this systematic review. The characteristics of the selected studies are provided in Table 1.

\section{Overview of Propolis \\ Composition and characterization of Propolis}

Propolis, commonly known as the "bee glue," is the third most important part of bee products [15, 17]. Propolis is a plant derived substance that honeybees make it by mixing their saliva containing specific enzymes and beeswax with exudate collected mostly from leaf and flower stems, buds, and bark cracks of various species of trees, and it contains multiple polyphenolic compounds, mostly flavonoids and phenolic acids [14, 15]. The word Propolis is made up of two Greek words, pro and polis, which mean "defense" and "city" or "community," respectively [15]. Propolis is used in the structure and maintenance of beehives as the defense mechanism [14]. Bees use it to smoother the inner surface, seal cracks and holes, maintain the internal temperature of the beehive, and prevent weathering and predator's attack. Moreover, due to its antimicrobial property, the internal environment remains aseptic [15].

Due to its main color, Propolis is divided into three classes, including green, red, and brown, with a melting point of around $65{ }^{\circ} \mathrm{C}$, but in some samples, its melting point goes higher, up to $100{ }^{\circ} \mathrm{C}[14,18]$. It is a resinous product with more than 300 compounds that vary based on types of hives, geographical origins, and seasons $[14,15]$, with some changes in its compounds profile due to extracting with water or ethanol [14]. Propolis compounds include phenolic acids, flavonoids, esters, diterpenes, sesquiterpenes, aromatic aldehydes, lignans, alcohols, amino acids, fatty acids, vitamins (thiamin, riboflavin, pyridoxine, $\mathrm{C}$, and $\mathrm{E}$ ), and minerals [14, 15]. The pharmacological properties of flavonoids are mostly due to their structural features as tricyclic compounds, resulting in attaching free radicals to their rings. The polyphenolic amount of different Propolis samples differs significantly, ranging from 143 to $324 \mathrm{mg}$ gallic acid equivalents/g and from 206 to $705 \mathrm{mg}$ quercetin equivalents/g of ethanolic extracts of Propolis (EEP), respectively. The phenolic content of Propolis, based on high-performance liquid chromatography (HPLC) analysis, commonly consists of chrysin, galangin, pinobanksin, pinostrobin, and pinocembrin, the last being the most abundant flavonoid in Propolis [14].

\section{Bioavailability of Propolis}

Propolis absorption and bioavailability is low due to its structure containing lipids, waxes, and resins in a complex substrate with a high molecular weight. The presence of various polyphenols with synergistic effects and forms used (natural fruit, juice, or extract) are essential contributors of bioavailability [34]. Poor bioavailability of polyphenols could be because of digestive instability, low transcellular efflux in intestinal cells, and rapid metabolism and excretion [35]. The conversion of the polyphenolic compounds, which are poorly bioavailable, to the smaller phenolic acids with increased bioavailability by the colonic microbiota and intestinal enzymes is an essential contributor in the beneficial effects of these compounds, and as gut microbiota varies between people, the absorption and metabolism differ individually $[36,37]$. Due to the high initial contents of phenolic compounds in Propolis compared to fruits and vegetables, its detected plasma levels were still high despite the low absorption rate [37]. The therapeutic effects of Propolis phenols in the bloodstream are restricted by their selective permeability across the blood-brain barrier and systemic elimination [34]. However, a recent study pointed that caffeic acid phenethyl ester (CAPE), a component found in Propolis, can cross the blood-brain barrier in rats [38]. It was reported that CAPE undergoes hydrolysis 


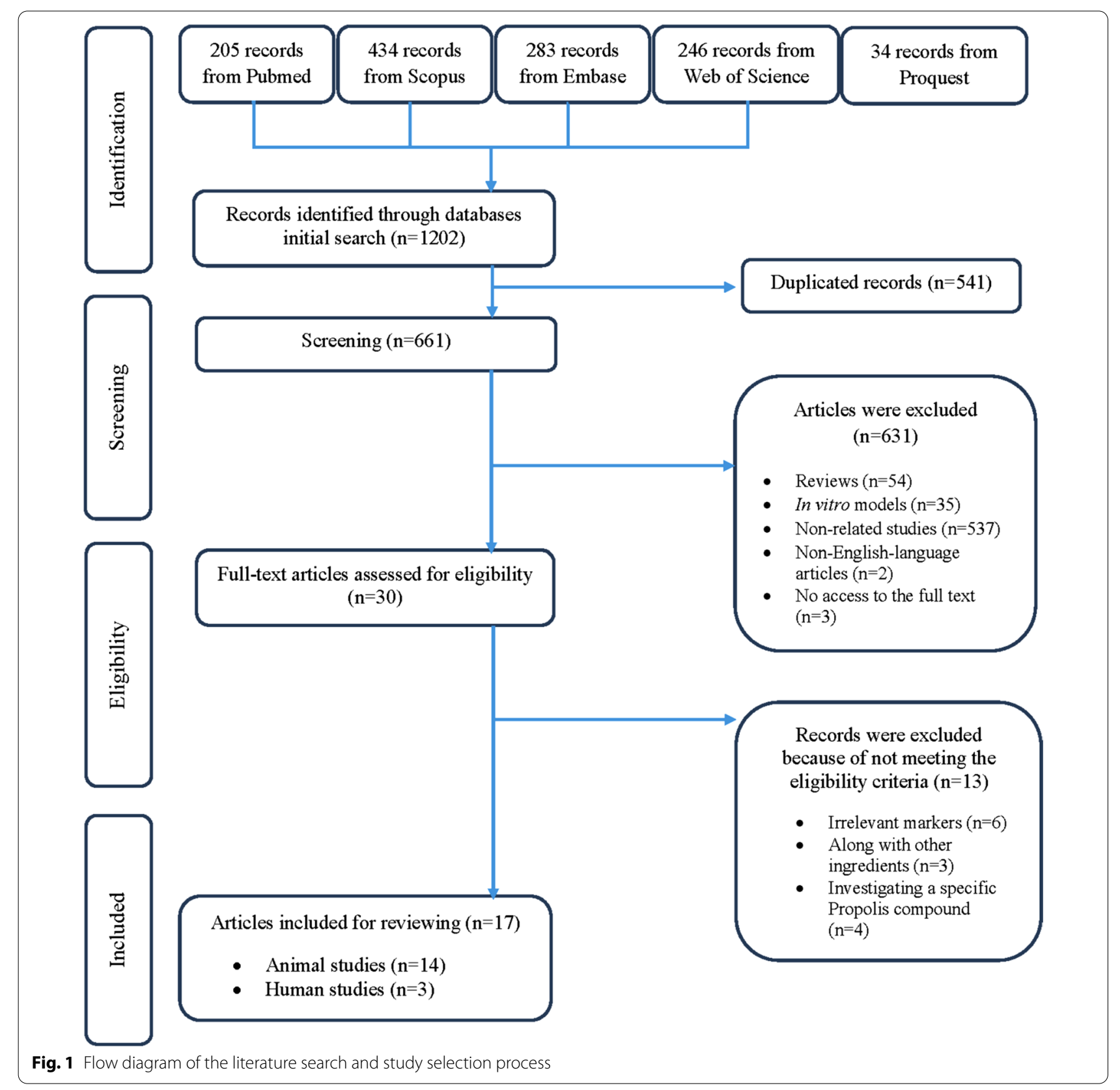

to caffeic acid within six hours of reaching the rat plasma [39]. Because of the lack of carboxylesterase enzyme in human plasma, which may be responsible for CAPE's hydrolysis, this type of conversion does not occur in humans [40]. Lipophilicity of Propolis polyphenols and metabolized derivatives is an important indicator of their permeability across the blood-brain barrier, in a way that less polar polyphenols and/or metabolites (i.e., O-methylated derivatives) have greater brain uptake compare to more polar ones (i.e., sulfated and glucuronidated derivatives) [41]. Polyphenols excretion in the urine differs individually, which may be related to aging, kidney function, or Propolis properties [14]. Continuing studies on the general health of Propolis consumers and the effects of this compound on renal function are necessary.

\section{Biological activities of Propolis}

Propolis has attracted attention in recent years because of its potential reported benefits in preventing and treating diseases, and a number of scientific articles have been widely investigated the bioactivity and health benefits of Propolis [14]. Anti-inflammatory, 


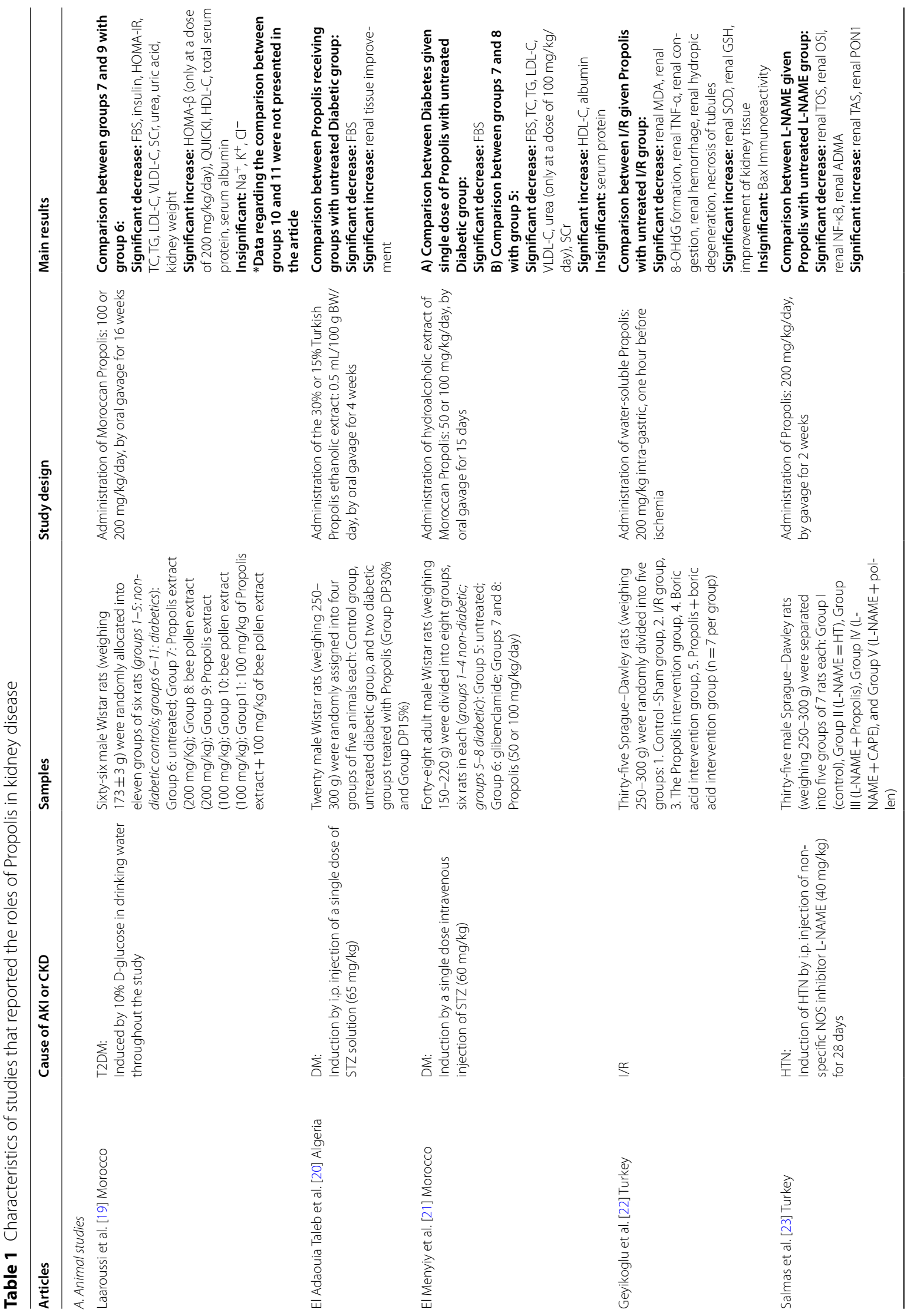




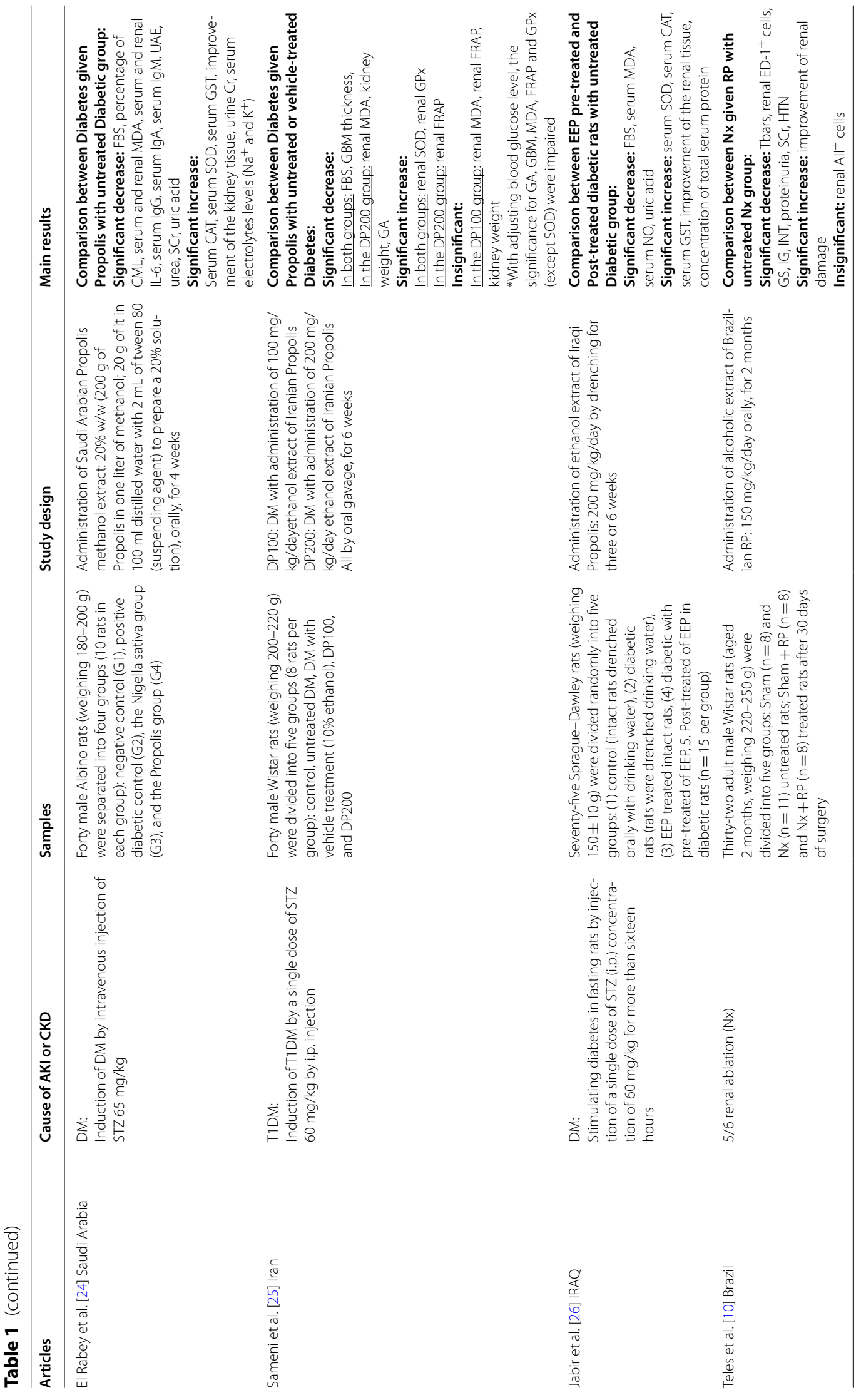




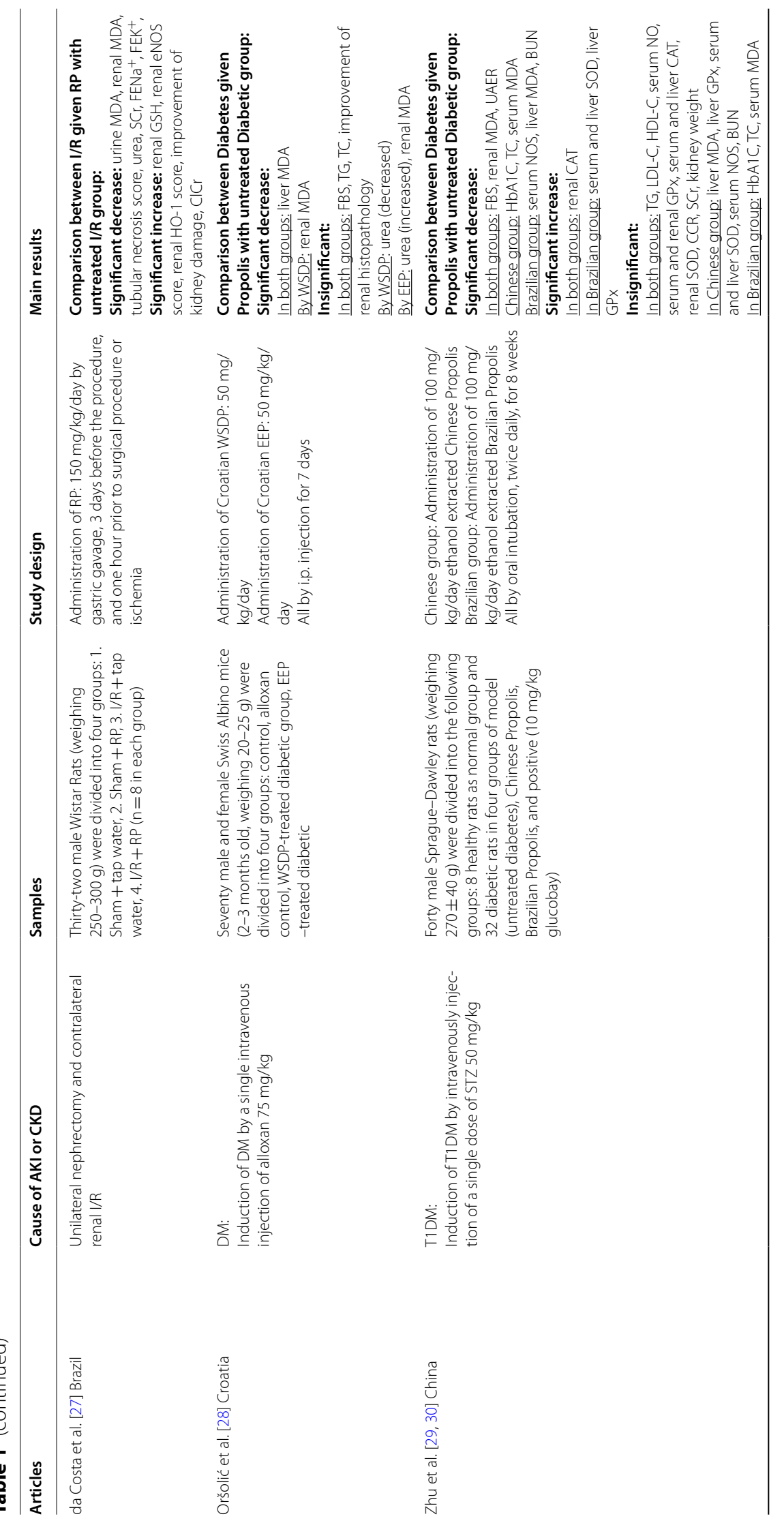




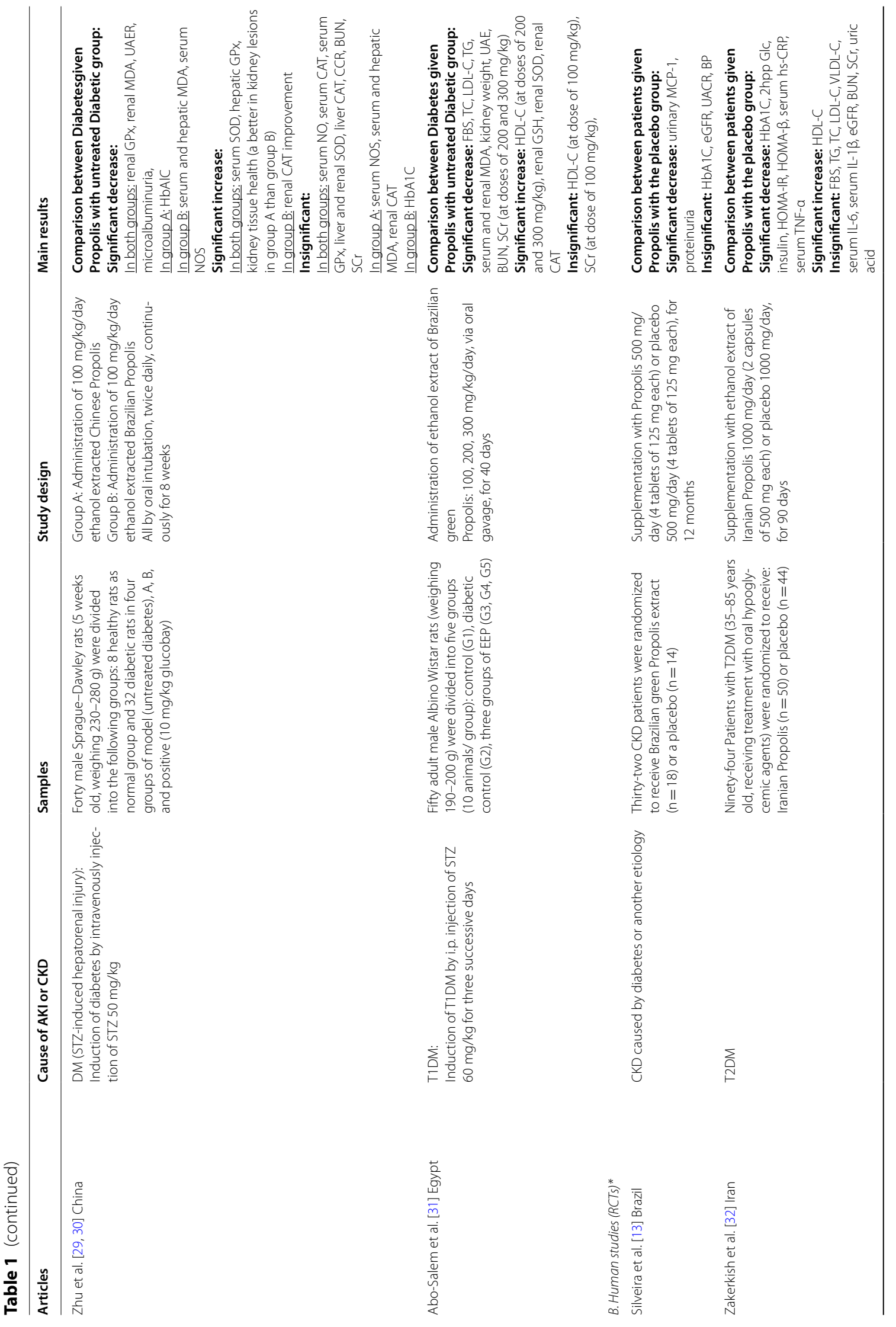




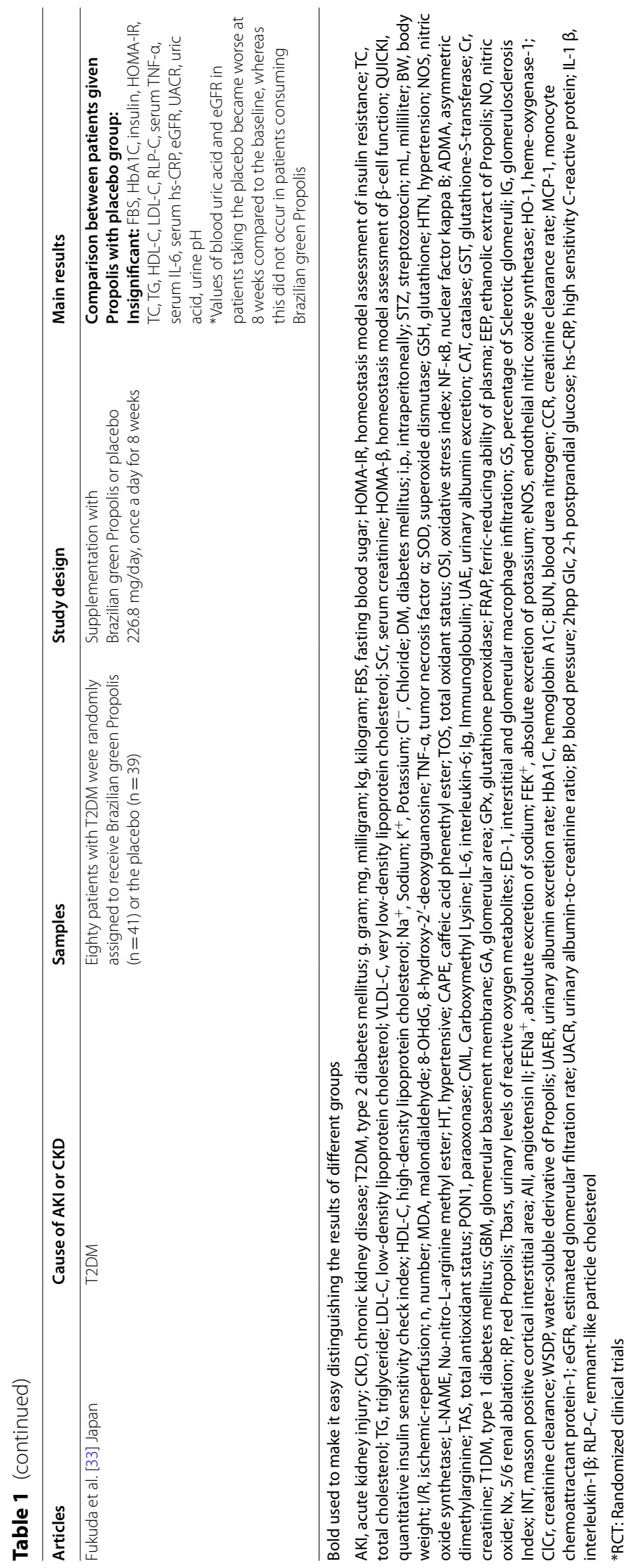


antioxidant, antiseptic, and immunomodulatory activities of Propolis, as well as its role in prevention and control of neoplastic disorders, and some chronic diseases like diabetes, atherosclerosis, HTN, neurodegenerative disorders, dental caries, and liver and kidney diseases, has probably come from the existing bioactive phytochemicals constituents and made it a valuable point for research [14-18]. The attenuation of adverse effects of the chemotherapeutic agents has been mentioned as another property for Propolis $[15,16]$. Notably, the Propolis type and the solvents used for its extraction determine the biological activity of this material [16]. Also, Propolis polyphenols have recently been defined as probiotics by an international consortium due to their selective metabolism by gut microbiota. Propolis polyphenols inhibit the growth of pathogenic bacteria and suppress gut pathogens' adherence to human gut cells, so it may improve gut health [14]. Additionally, due to antimicrobial (the most extensively reported property of Propolis), antiseptic, anti-inflammatory, antioxidant, and immunomodulatory effects of Propolis, it has been widely used as an external treatment for wounds and burns. These properties perhaps increase cell proliferation in the skin and activate the remodeling of the skin tissue [16]. Propolis was also researched in cosmetic industries. The studies reported that it could act as a sunscreen agent; therefore, it can be used as an ingredient of sunscreen cosmetics [15]. The Propolis trade is growing, and it is found commercially in the forms of lozenges, mouthwash, toothpaste, creams, dentifrices, cough syrups, gels, wine, powder, cake, soap, chewing gums, and tablets [14, 42]. Sales on Propolis containing products for oral health and wound care appear at the top of the category list [14].

\section{Side effects and toxic properties of Propolis}

Clinical studies in mice and humans show that Propolis and its compounds are usually well-tolerated and nontoxic when used in moderation [43-45]. However, it must be reminded that few human trials include side effects and toxicity of Propolis as an outcome measure [14].

In a reported case, a 59-year-old man with cholangiocarcinoma who was supplementing with Propolis developed AKI, and his kidney function improved after hemodialysis and withdrawal of Propolis. However, he continued the consumption of Propolis for his cancer because he was uncertain about the role of the Propolis in the development of AKI. Renal function worsened again and improved with discontinuation. Renal biopsy was not taken from the patient in this study; however, the likely side effects of the Propolis became a topic of interest. The probable mechanism proposed in this study was the CAPE mediated inhibition of cyclooxygenase and inducible nitric oxide synthase (iNOS) pathways as it happens in nonsteroidal anti-inflammatory drug-related AKI [46].

Based on previous animal studies, the safe concentration of Propolis for generally healthy humans is approximately $1.4 \mathrm{mg} / \mathrm{kg} /$ day or $70 \mathrm{mg} /$ day [47]. Interestingly, studies have concluded that even using $150 \mathrm{mg}$ of pinocembrin, a component of Propolis as a single dose, is safe [45]. The median lethal dose (LD50) of Propolis extract while given to mice is higher than $7.34 \mathrm{~g} / \mathrm{kg}$, assures human therapeutic dosage safety $[48,49]$. However, determining the proper dose of Propolis because of the different studied populations, dosing regimens, patient's compliance, and purity of the product is difficult. Also, differences in Propolis's phenolic compounds and their bioactivity due to different geographical areas make it difficult to determine the exact appropriate dosage [14]. Hypersensitivity is the more common adverse effect of Propolis, especially in topical use, which causes allergic reactions, swelling, dermatitis, and urticaria [50]. Dermatitis induced by Propolis was first reported by beekeepers; over time, as the usage of Propolis developed, non-occupational cases were also reported [51]. 1.2-6.6\% of individuals with dermatitis were sensitive to Propolis [52]. Allergy to Propolis is more common in children; therefore, patch warnings were advised for dermatological use in young children [53-55].

\section{Propolis and metabolic variables (glycemic and lipid profile) in kidney disease Glycemic profile}

Animal studies The effects of Propolis supplementation on glycemic parameters have been investigated in ten among the fourteen animal studies. In a study conducted by Laaroussi et al., it was revealed that Moroccan Propolis administration ( 100 or $200 \mathrm{mg} / \mathrm{kg} /$ day) to diabetic rats for 16 weeks resulted in significantly decreased fasting blood sugar (FBS), serum insulin, and homeostasis model assessment of insulin resistance (HOMA-IR), and increased homeostasis model assessment of $\beta$-cell function (HOMA- $\beta$ ) (only at a dose of $200 \mathrm{mg} / \mathrm{kg} /$ day) and quantitative insulin sensitivity check index (QUICKI) [19]. In another study by El Adaouia Taleb et al., it was reported that administration of $30 \%$ or $15 \%$ Turkish Propolis ethanolic extract at the dosage of $0.5 \mathrm{ml} / 100 \mathrm{~g} \mathrm{BW} /$ day in diabetic rats for 4 weeks significantly lowered FBS levels, while the rate in 30\% propolis treated group had normalized [20]. Besides, in El Menyiy et al. experimental study, 50 or $100 \mathrm{mg} / \mathrm{kg} /$ day hydroalcoholic extract of Moroccan Propolis was administered to diabetic rats and the levels of FBS one, two, and three hours, as well as 15 days after first administration, were measured. It was shown that Propolis at both doses could significantly decrease the FBS levels, and it was more potent than glib- 
enclamide at an amount of $100 \mathrm{mg} / \mathrm{kg} /$ day [21]. In a study by Rabey et al., administration of Propolis methanol extract $(20 \% \mathrm{w} / \mathrm{w})$ to diabetic rats for 4 weeks resulted in a significant reduction of FBS and percentage of carboxymethyl lysine (CML), as a marker of advanced glycation end products (AGEs) [24]. Moreover, Sameni et al. reported a significantly reduced FBS after 6 weeks of 100 and $200 \mathrm{mg} / \mathrm{kg} /$ day EEP administration in diabetic rats [25]. In another study, receiving $200 \mathrm{mg} / \mathrm{kg} /$ day EEP for 3 weeks in two groups of rats, one group before induction of diabetes and another group after induction, showed a significant reduction in FBS, and it was more pronounced in the treatment group than the pre-DM-induction group [26]. Zhu et al. administered $100 \mathrm{mg} / \mathrm{kg} /$ day ethanol extracted Chinese or Brazilian Propolis for 8 weeks to diabetic rats and reported that the intervention could reduce FBS in both groups except the hemoglobin A1C (HbA1C) that was only decreased in the Chinese Propolis recipient group [29]. Another study by Zhu et al., with the same dosage and duration of supplementation in diabetic rats, showed significant reductions in $\mathrm{HbA1C}$ only in the Chinese Propolis group [30]. In another study by Abo-Salem et al., 100, 200, $300 \mathrm{mg} / \mathrm{kg} /$ day ethanol extract of green Propolis administration for 40 days significantly decreased FBS in all supplementation dosages in diabetic rats [31]. However, Orsolic et al. showed that in diabetic mice fed $50 \mathrm{mg} / \mathrm{kg} /$ day water or ethanol extract of Propolis for 1 week, FBS alterations were not considerable in both groups [28].

Human studies All three human studies included in this article have reported the effects of Propolis supplementation on glycemic parameters. In the study by Fukuda et al., green Propolis supplementation with a dose of $226.8 \mathrm{mg} /$ day for 8 weeks in patients with type 2 diabetes did not make any significant changes in HOMA-IR, FBS, HbA1c, and insulin levels [33]. In another study, Silveira et al. conducted a double-blind, placebo-controlled clinical trial on CKD patients and reported that Propolis did not result in any significant changes in HbA1c following green Propolis supplementation with a $500 \mathrm{mg} /$ day dose for 1 year [13]. However, Zakerkish et al. showed that Propolis supplementation of $1000 \mathrm{mg} /$ day for 90 days in T2DM patients could significantly decrease HbA1C, 2-h postprandial glucose (2hpp Glc), insulin, HOMA-IR, and HOMA- $\beta$ levels but has no significant effect on FBS concentrations [32].

\section{Lipid profile}

Animal studies The effects of Propolis on lipid profile have been reported in five out of the fourteen animal models of kidney disease studies. In a study by Laaroussi et al. on diabetic rats, 100 or $200 \mathrm{mg} / \mathrm{kg} /$ day Moroccan Propolis admin- istration for 16 weeks resulted in a significant decrease in total cholesterol (TC), triglyceride (TG), low-density lipoprotein cholesterol (LDL-C), and very low-density lipoprotein cholesterol (VLDL-C), and increase in high-density lipoprotein cholesterol (HDL-C) levels [19]. Similarly, in another study by El Menyiy et al., the significant decrease in terms of TC, TG, LDL-C, and VLDL-C and increase in HDL-C levels were reported in diabetic rats receiving 50 or $100 \mathrm{mg} / \mathrm{kg} /$ day hydroalcoholic extract of Moroccan Propolis for 15 days [21]. Zhu et al. administered $100 \mathrm{mg} / \mathrm{kg} / \mathrm{day}$ ethanol extracted Chinese or Brazilian Propolis to diabetic rats for 8 weeks and reported that the intervention could reduce serum TC levels in only the Chinese Propolis group but had not any significant effects on serum concentrations of TG, LDL-C, and HDL-C in both groups [29]. Also, AboSalem et al. reported that the administration of EEP (100, 200 , and $300 \mathrm{mg} / \mathrm{kg} /$ day) to diabetic rats for 40 days significantly reduced serum TC, LDL-C, and TG levels in all doses, and significantly increased HDL-C level at the doses of 200 and $300 \mathrm{mg} / \mathrm{kg} /$ day [31]. In contrast, Orsolic et al. reported that water and ethanol extracted Propolis given at the dose of $50 \mathrm{mg} / \mathrm{kg} /$ day to diabetic rats for seven days did not change serum TG and TC levels, the result was independent of the Propolis preparation methods [28].

Human studies Among the three selected human studies, two of them assessed the effectiveness of Propolis on dyslipidemia. In a trial by Zakerkish et al., the levels of HDL-C significantly increased in diabetic patients following Propolis intake of $1000 \mathrm{mg} /$ day for 90 days; however, the serum levels of TG, TC, LDL-C, and VLDL-C did not show any significant changes in their reports [32]. In another study involving diabetic patients, Fukuda et al. reported that $226.8 \mathrm{mg} /$ day Brazilian green Propolis for 8 weeks did not improve lipid profile (serum levels of TG, TC, LDL-C, HDL-C, and remnant-like particle cholesterol (RLP-C)) significantly [33].

\section{Propolis and oxidative stress indices in kidney disease Animal studies}

Eleven out of fourteen animal studies included in this article have evaluated the possible effects of Propolis on oxidative parameters. In a study by Rabey et al., the administration of Propolis methanol extract $(20 \% \mathrm{w} / \mathrm{w})$ to diabetic rats for 4 weeks resulted in a significant reduction of serum and renal tissue malondialdehyde (MDA) and a significant increase of serum catalase (CAT), superoxide dismutase (SOD), and glutathione-S- transferase (GST) [24]. Orsolic et al. showed that in diabetic mice fed by $50 \mathrm{mg} /$ $\mathrm{kg}$ /day water or ethanol extract of Propolis for 1 week, liver MDA levels in both groups and renal MDA only in the water extract group significantly decreased [28]. Zhu et al. administered $100 \mathrm{mg} / \mathrm{kg} /$ day ethanol extracted 
Chinese or Brazilian Propolis for 8 weeks to diabetic rats, and reported that the intervention could reduce renal MDA in both groups, serum MDA in the Chinese Propolis group, and serum nitric oxide synthetase (NOS) and liver MDA in the Brazilian Propolis group, and also could increase renal CAT in both groups and serum and liver SOD and liver glutathione peroxidase (GPx) in Brazilian Propolis group. Despite these, they did not see any significant effects on serum nitric oxide (NO), serum and renal GPx, serum and liver CAT, and renal SOD alterations in this study [29]. In another study done by Zhu et al., with the same dosage and duration of supplementation in diabetic rats, there were significant reductions in renal GPx and MDA in both groups and serum and hepatic MDA and serum NOS only in the Brazilian Propolis group, a significant increase in serum SOD and hepatic GPx in both groups, and renal CAT only in Brazilian Propolis group, while alterations of serum NO, serum CAT, serum GPx, liver and renal SOD, and liver CAT were insignificant [30]. In another study by da Costa et al., involving rats exposed to unilateral nephrectomy and contralateral renal ischemic-reperfusion ( $\mathrm{I} / \mathrm{R})$, administration of $150 \mathrm{mg} / \mathrm{kg} /$ day of red Propolis (RP) 3 days before the procedure and one hour prior to surgical procedure or ischemia caused a significant decrease in urine and renal tissue MDA and a significant increase in renal tissue glutathione (GSH), renal endothelial NOS (eNOS) score, and renal hemeoxygenase-1 (HO-1) score [27]. Also, Teles et al. reported that in $5 / 6$ renal removed rats, administration of $150 \mathrm{mg} /$ $\mathrm{kg} /$ day alcoholic extract of RP for 2 months led to a significant decrease in urinary levels of reactive oxygen metabolites (T-bars) [10]. Salmas et al. found out that in hypertensive rats, administration of $200 \mathrm{mg} / \mathrm{kg} /$ day Propolis for 2 weeks led to a significant decrease in renal tissue total oxidant status (TOS) and oxidative stress index (OSI), as well as a significant increase of total antioxidant status (TAS) and paraoxonase (PON1) [23]. Moreover, Geyikoglu et al. discovered significantly decreased renal tissue MDA and 8-hydroxy-2'-deoxyguanosine (8-OHdG) formation in rat kidney cells and a considerably increased renal tissue SOD and GSH after $200 \mathrm{mg} / \mathrm{kg}$ administration of watersoluble Propolis one hour before ischemia in rats exposed to I/R [22]. Sameni et al. administered 100 and $200 \mathrm{mg} /$ $\mathrm{kg} /$ day EEP for 6 weeks to diabetic rats and reported that the intervention could significantly increase renal tissue SOD and GPx in both groups, and ferric-reducing ability of plasma (FRAP) only by $200 \mathrm{mg} / \mathrm{kg}$ dosage, and reduce renal tissue MDA again in only $200 \mathrm{mg} / \mathrm{kg}$ dosage [25]. Also, in a study by Abo-Salem et al., 100, 200, and $300 \mathrm{mg} /$ $\mathrm{kg} /$ day ethanol extract of green Propolis administration for 40 days significantly decreased serum and renal tissue MDA, and increased renal tissue GSH, SOD, and CAT in all dosages of supplementation in diabetic rats [31]. In another study, receiving $200 \mathrm{mg} / \mathrm{kg} /$ day EEP for 3 weeks in two groups of rats, one group before induction of diabetes and another group after induction of it, showed significant reductions in serum MDA and NO, and significant elevation in serum SOD, CAT, and GST concentrations [26].

\section{Propolis and inflammation biomarkers in kidney disease Animal studies}

Four of the fourteen animal studies assessed the effects of Propolis on inflammation status. Salmas et al. reported that administering $200 \mathrm{mg} / \mathrm{kg} /$ day Propolis for 2 weeks in hypertensive rats led to a significant decrease in renal levels of nuclear factor kappa B (NF-kB) [23]. Moreover, Geyikoglu et al. observed significantly decreased renal levels of tumor necrosis factor $\alpha$ (TNF- $\alpha$ ) after administration of $200 \mathrm{mg} /$ $\mathrm{kg}$ water-soluble Propolis one hour before ischemia in rats exposed to I/R [22]. Also, in Rabey et al. study, supplementing diabetic rats with Propolis methanol extract $(20 \% \mathrm{w} / \mathrm{w})$ for 4 weeks resulted in a significant reduction in the levels of serum and renal interleukin-6 (IL-6) and serum immunoglobulins (IgG, IgA, and IgM) [24]. Similarly, in a study by Teles et al. on rats with $5 / 6$ renal ablation, alcoholic extracted RP intake of $150 \mathrm{mg} / \mathrm{kg} /$ day for 2 months significantly decreased renal tissue inflammation (interstitial and glomerular macrophage infiltration; as ED-1 ${ }^{+}$cells) [10].

\section{Human studies}

The effects of Propolis on inflammation biomarkers in kidney disease were investigated in all three human studies. In a randomized controlled trial by Silveira et al., Brazilian green Propolis supplementation at the dosage of $500 \mathrm{mg} /$ day in CKD patients for 12 months significantly decreased urinary monocyte chemoattractant protein-1 (MCP-1) levels [13]. Similarly, in Zakerkish et al. study, Propolis intake at the dosage of $1000 \mathrm{mg} /$ day in patients with T2DM for 90 days significantly caused serum reduction of high sensitivity C-reactive protein (hs-CRP) and TNF- $\alpha$ levels but did not significantly change serum levels of interleukin-1 $\beta$ (IL-1 $\beta$ ) and IL-6 [32]. Conversely, Fukuda et al. reported that administration of Brazilian green Propolis at the dosage of $226.8 \mathrm{mg} /$ day in diabetic patients for 8 weeks did not change the serum levels of TNF- $\alpha$, IL-6, and hs-CRP remarkably [33].

\section{Propolis and renal damage morphology and structure in kidney disease \\ Animal studies}

Twelve out of the fourteen animal studies evaluated the potential effects of Propolis on the morphology and structure of kidney. In a study conducted by El Adaouia Taleb et al., the histopathological assessment indicated the DN manifestations in untreated diabetic rats, including mesangial expansion, glomerulosclerosis (GS), and tubular 
atrophy. By administering $0.5 \mathrm{ml} / 100 \mathrm{~g} \mathrm{BW} /$ day of $30 \%$ or 15\% Turkish Propolis ethanolic extract for 4 weeks, totally healthy tubules, as well as fewer glomeruli at the mesangial expansion and GS stages, were observed. The $30 \%$ Propolis was more effective than the $15 \%$ in preserving renal glomeruli [20]. In Geyikoglu et al. study, pretreatment with $200 \mathrm{mg} / \mathrm{kg}$ water-soluble extract of Propolis in rats with renal $I / R$ injury one hour before ischemia significantly decreased the renal congestion, renal hemorrhage, renal hydropic degeneration, and tubular necrosis; however, the number of Bax-positive (a pro-apoptotic protein) cells did not change significantly [22]. Also, Jabir et al. assessed the effects of $200 \mathrm{mg} / \mathrm{kg} /$ day EEP in diabetic rats for 3 weeks. In the untreated diabetic rats, renal histopathological changes were reported as follows: severe vascular congestion, atrophy, and destruction, infiltration of red blood cells into the interstitium and tubules, presence of edematous and inflamed cells, perivascular tissue necrosis, and mild to moderate hyaline degeneration. In the diabetic rats pretreated with EEP (before streptozotocin (STZ) injection), Propolis improved the histopathological changes, as kidneys had mild to moderate vascular congestion and low infiltration of red blood cells into the interstitium, and Bowman's capsules were preserved. In the diabetic rats post-treated with EEP (after STZ injection), the assessment showed mild vascular congestion and tubular dilation, preserved Bowman's capsule, and restored renal tissue near-normal conditions; so in conclusion, Propolis improved the health and integrity of the kidney tissue [26]. In another experimental study, Rabey et al. examined the effects of methanolic extracted Propolis $(20 \% \mathrm{w} / \mathrm{w})$ on renal tissue for 4 weeks. In the control diabetic group, the observed pathological change in kidney structure was collapsed glomerular tuft with marked tubular atrophy, associated with interstitial inflammation and hemorrhage. Treating these diabetic rats with Propolis caused the restoration of most of the histopathologic changes in the kidney tissue nearly normal [24]. In another study by Zhu et al., there were increased volume and proliferation of mesangial cells in the glomeruli and vacuolization of renal tubular epithelial cells and casts in control diabetic rats. There was only the proliferation of mesangial cells in the glomeruli in the Chinese Propolis receiving group; in addition to this change, vacuolization of renal tubular epithelial cells was also observed in the kidneys of the Brazilian Propolis group. Overall, kidney health was significantly increased with the administration of $100 \mathrm{mg} / \mathrm{kg} /$ day of ethanol extracted Chinese or Brazilian Propolis for 8 weeks in this study; however, Chinese Propolis could improve kidney injuries better than the Brazilian one [30]. In Sameni et al. study, an intake of 100 or $200 \mathrm{mg} / \mathrm{kg}$ /day EEP in diabetic rats for 6 weeks significantly decreased glomerular basement membrane (GBM) thickness. Besides, Propolis at the dose of $200 \mathrm{mg} / \mathrm{kg} /$ day caused a significant reduction in kidney weight and glomerular area (GA) [25]. The kidney weight changes in diabetic rats were also investigated in three other studies. Similarly, in the Abo-Salem et al. study, administration of EEP $(100,200$, and $300 \mathrm{mg} / \mathrm{kg} /$ day $)$ for 40 days significantly inhibited kidney enlargement [31]. Furthermore, in a study by Laaroussi et al., with administering 100 or $200 \mathrm{mg} / \mathrm{kg} /$ day Moroccan Propolis to diabetic rats for 16 weeks, the kidney weight decreased [19]. Moreover, in Zhu et al. study, Chinese or Brazilian EEP at the dose of $100 \mathrm{mg} / \mathrm{kg} /$ day for 8 weeks did not affect kidney weight [29]. Effects of RP at a dose of $150 \mathrm{mg} / \mathrm{kg} /$ day in experimental models of CKD were investigated in two studies. Teles et al. reported that alcoholic extract of RP treatment for 2 months significantly decreased the percentage of GS (\%GS), GS Index (IG), and Masson positive cortical interstitial area (as a marker of renal fibrosis) in rats with 5/6 renal ablation. As a result, RP treatment recovered the renal structural deterioration in experimental models with nephropathy [10]. Similarly, in da Costa et al. experimental study, assessment of the renal tissue showed considerable structural damages in rats exposed to unilateral nephrectomy and contralateral renal I/R, including tubular dilation and necrosis (inflammatory cell infiltration and cellular edema in the tubular interstitium) in the renal cortex and outer medulla. Red Propolis administration 3 days before the procedure and one hour prior to surgical procedure or ischemia attenuated kidney damages and significantly decreased tubular necrosis score [27]. Conversely, in Orsolic et al. study, renal examination revealed corpuscular changes (narrowing or reduction of Bowman's space due to the expansion of mesangial and/ or endothelial cells of the glomerulus, and the presence of columnar cells in the parietal layer of Bowman's capsule), tubular alterations (the presence of necrotic cells, basophilic cells, cytoplasmic vacuolization, vacuole-like spaces in the tubular lumen, epithelial flattening with or without intraluminal eosinophilic mass, and dilated tubules), and interstitial disorders, and further impaired function in the kidneys of control diabetic mice. Administration of $50 \mathrm{mg} / \mathrm{kg} /$ day of Propolis [EEP or water-soluble derivative of Propolis (WSDP)] for seven days did not improve renal histopathology in diabetic mice. However, there were fewer basophilic and more dilated tubules in the EEP group, and more extensive lymphocyte infiltrations, as well as more dilated tubules in the outer cortex in the WSDP group, compared to control mice [28].

\section{Propolis and renal function in kidney disease Animal studies}

Among the fourteen selected animal studies, six had evaluated the impact of Propolis on renal function. Rabey et al. showed that $20 \% \mathrm{w} / \mathrm{w}$ Propolis methanol extract 
supplementation for 4 weeks significantly decreased urinary albumin excretion (UAE) in diabetic rats [24]. Also, in a study by Abo-Salem et al., 100, 200, $300 \mathrm{mg} / \mathrm{kg} /$ day ethanol extract of green Propolis administration for 40 days significantly decreased UAE in all dosages of supplementation in diabetic rats [31]. In two other studies, administering $100 \mathrm{mg} / \mathrm{kg} /$ day ethanol extracted Chinese or Brazilian Propolis for 8 weeks in diabetic rats could decrease urinary albumin excretion rate (UAER) in both groups but had no significant effects on creatinine clearance rate (CCR) $[29,30]$. In another study by da Costa et al., involving rats exposed to unilateral nephrectomy and contralateral renal I/R, administration of $150 \mathrm{mg} / \mathrm{kg} /$ day of RP 3 days before the procedure and one hour prior to surgical procedure or ischemia caused a significant increase in creatinine clearance $(\mathrm{ClCr})$ [27]. Also, Teles et al. reported that in $5 / 6$ renal removed rats, administration of $150 \mathrm{mg} / \mathrm{kg} /$ day alcoholic extract of RP for 2 months led to a significant decrease in proteinuria [10].

\section{Human studies}

All of the human studies included in this article have assessed the effects of Propolis on renal function. In the study by Fukuda et al., Propolis supplementation with a $226.8 \mathrm{mg} /$ day dose for 8 weeks in patients with type 2 diabetes did not change estimated GFR (eGFR) and urinary albumin-to-creatinine ratio (UACR) significantly [33]. Also, Zakerkish et al. reported that $1000 \mathrm{mg} /$ day of Propolis supplementation for 90 days in T2DM patients had no significant effects on eGFR [32]. Silveira et al. showed that $500 \mathrm{mg} /$ day Propolis supplementation for 1 year in CKD patients, although had no significant effects on eGFR and UACR, could remarkably decrease proteinuria [13].

\section{Propolis and renal function indicators in kidney disease Animal studies}

From the fourteen animal articles reviewed, eleven studies evaluated the effects of Propolis on renal function indicators. In an experimental study by Laaroussi et al. on diabetic rats, administering 100 or $200 \mathrm{mg} / \mathrm{kg} / \mathrm{day}$ Moroccan Propolis for 16 weeks significantly decreased $\mathrm{SCr}$, urea, and uric acid, and increased total serum protein and albumin; however, serum level of electrolytes including Sodium $\left(\mathrm{Na}^{+}\right)$, Potassium $\left(\mathrm{K}^{+}\right)$, and Chloride $\left(\mathrm{Cl}^{-}\right)$did not show any significant changes [19]. In another study conducted by El Menyiy et al., administering 50 or $100 \mathrm{mg} / \mathrm{kg} /$ day hydroalcoholic extract of Moroccan Propolis for 15 days to diabetic rats caused a significant decrease in urea (only at a dose of $100 \mathrm{mg} / \mathrm{kg}$ / day) and $\mathrm{SCr}$, and increase in serum albumin concentrations. The levels of serum protein did not change significantly [21]. Two studies reported the effects of $200 \mathrm{mg} /$ $\mathrm{kg} /$ day Propolis intake on CKD experimental models. In Salmas et al. study, Propolis intake for 2 weeks resulted in a significant decrease in renal asymmetric dimethylarginine (ADMA) levels, a NO synthase inhibitor, in hypertensive rats [23]. In another study on diabetic rats by Jabir et al., EEP administration for 3 weeks decreased the serum uric acid levels and increased the total serum protein concentrations, both significantly [26]. Similarly, Rabey et al. reported that administration of methanol extract of Propolis $(20 \% \mathrm{w} / \mathrm{w})$ for 4 weeks significantly decreased the serum levels of urea, creatinine $(\mathrm{Cr})$, and uric acid, and increased the urinary $\mathrm{Cr}$ and the serum electrolytes levels (restoration of $\mathrm{Na}^{+}$and $\mathrm{K}^{+}$to normal levels) in diabetic rats [24]. Moreover, the effectiveness of $150 \mathrm{mg} / \mathrm{kg} / \mathrm{day}$ of RP was examined in two articles. In Teles et al. study, a significant decrease in SCr levels and systemic blood pressure (BP) in rats with renal ablation was reported following alcoholic extracted RP intake for 2 months. However, no difference was noted for the levels of renal interstitial cells positive to angiotensin II (AII ${ }^{+}$cells), which are involved in the HTN development [10]. Moreover, in da Costa et al. study, a statistically significant decrease in serum levels of urea, $\mathrm{Cr}$, and absolute excretion of $\mathrm{Na}^{+}$and $\mathrm{K}^{+}$(as markers of functional tubular viability and renal tubular injury) was noticed following RP pretreatment in rats exposed to unilateral nephrectomy and contralateral renal I/R [27]. Notably, Abo-Salem et al. conducted a study in diabetic rats and observed that an intake of EEP (100, 200, $300 \mathrm{mg} /$ $\mathrm{kg} /$ day) for 40 days significantly decreased blood urea nitrogen (BUN) (at the three tested doses) and SCr levels (except at dose of $100 \mathrm{mg} / \mathrm{kg} /$ day) [31]. The effectiveness of Propolis types (Chinese or Brazilian) has been examined in two articles. Zhu et al. administered $100 \mathrm{mg} / \mathrm{kg} /$ day of EEP to diabetic rats for 8 weeks and reported that only Brazilian Propolis significantly reduced BUN levels, and $\mathrm{SCr}$ did not change significantly by both types [29]. In another similar study by Zhu et al., BUN and SCr levels did not change significantly, independent of Propolis types [30]. Effects of Propolis preparations $(50 \mathrm{mg} / \mathrm{kg} /$ day of ethanolic or aqueous extract of Propolis for 7 days) have been evaluated in Orsolic et al. study. It was shown that serum urea did not change by both preparation methods of Propolis in diabetic mice [28].

\section{Human studies}

All three randomized clinical trials examined the impact of Propolis on renal function indicators. Silveira et al. reported that BP did not change significantly in CKD subjects supplemented with $500 \mathrm{mg} /$ day Brazilian green Propolis for 12 months [13]. Zakerkish et al. conducted an RCT on diabetic patients and revealed that Propolis supplementation of $1000 \mathrm{mg} /$ day for 90 days did not 
significantly affect BUN, SCr, and serum uric acid levels [32]. Similarly, in another study by Fukuda et al., it was shown that the administration of $226.8 \mathrm{mg} /$ day Brazilian green Propolis in diabetic subjects for 8 weeks had no effect on the levels of serum uric acid and urine $\mathrm{pH}$ [33].

\section{Discussion}

In this systematic review, the effects of Propolis, as a nutrient substance with antioxidant and anti-inflammatory properties, on clinical course of kidney disease and the associated markers were evaluated. The previous systematic review suggests that Propolis may be beneficial for glycemic control in adults with T2DM [56]. The current study showed that Propolis supplementation had a potential effect on improving $2 \mathrm{hpp}$ Glc [32] and the percentage of CML [24] in kidney disease. The studies regarding HOMA- $\beta[19,32]$ and QUICKI [19] were not enough to make a judgment. On the other hand, eight studies showed a significant reduction of FBS following Propolis supplementation [19-21, 24-26, 30, 31], although no considerable effects were reported in the other three studies [28, 32, 33]. Moreover, despite the significant decrease of HbA1c in three studies [29, 30, 32], two trials showed insignificant reductions [13, 33]. However, the results regarding insulin levels and HOMA-IR were controversial; in three studies [19, 32, 33], the levels decreased, but only in two of them these alterations were significant, suggesting improving the insulin sensitivity $[19,32]$. These differences could be explained by the changes in dose and duration of intervention, type and geographical origin of Propolis, and the season in which it was obtained; and also, preparation of Propolis extract with water or ethanol may vary the Propolis main components. Notably, these discrepancies may also be due to variations in sex, age, genetic, physical activity, nutritional intake, gut microbiota, and other confounders, such as the family history of diseases in clinical trial [57]. As a matter of fact, animal studies could be controlled better than human ones in terms of confounders. Therefore, well-designed clinical trials are needed to compare the significant effects of different types of Propolis. The possible mechanisms underlying the glycemic control achieved by Propolis supplementation could be attributed to the existing bioactive compounds, which could increase insulin production or/and cellular sensitivity to it [58]. In a study by Zhang et al. [59], Propolis extract compared to synthetic $\alpha$-glycosidase inhibitor such as acarbose showed more potent inhibitory effects on $\alpha$-glycosidase and intestinal sucrase. Also, Matsui et al. [60] pointed that the anti-hyperglycemic effect of Propolis comes from the inhibition of glucose production from dietary carbohydrates and highly suggested this resinous substance for controlling or delaying the postprandial glucose elevation and improving insulin resistance as well. Furthermore, Propolis extract not only reduces the intestinal absorption of carbohydrates, triggers glucose uptake and the translocation of insulinsensitive glucose transporter (GLUT) 4 in peripheral tissue like skeletal muscle cells by inducing phosphorylation of both phosphatidylinositol 3-kinase (PI3K) and 5 '-adenosine monophosphate-activated protein kinase (AMPK) [32, 61]. Of note, Propolis may suppress the gluconeogenic genes in hepatocellular cells, especially the glucose-6-phosphatase coding gene [62]. Increasing glycolysis and glucose utilization in the liver has been suggested as another route for Propolis's mechanism of action [32]. Chronic hyperglycemia is the main cause of micro-and macro-vascular complications of diabetes and the leading reason for CKD $[63,64]$. Most previous studies have found that renal glucose uptake in diabetic patients was increased in both post-absorptive and postprandial states; however, muscle glucose uptake was either normal or reduced [65, 66]. Compensated increased glucose uptake in the kidney not merely due to the mass action effects of hyperglycemia but because of increased renal glucose fractional extraction by overexpression of GLUT-1 increases the generation of reactive oxygen species (ROS) and activates mediators of intrarenal inflammation. It also suppresses intracellular antioxidant defense mechanisms, eventually contributing to OS, and leading to renal tissue dysfunction [63, $64,66-68]$. Oxidative stress, as one of the major factors of DN, may activate NF- $\mathrm{kB}$, which controls the expression of a cascade of pro-inflammatory molecules contributing to the progression of apoptosis and renal dysfunction $[57,68]$. Also, increased formation of AGEs caused by persistent hyperglycemia induces the AGERAGE (advanced glycation end products-receptor for advanced glycation end products) interaction in the kidney, which contributes to the activation of intracellular ROS generation [63]. Briefly, stimulating the ROS-mediated pathways such as NF- $\mathrm{KB}$, protein kinase $\mathrm{C}$ (PKC), angiotensin II synthesis, polyol pathway flux, hexosamine pathway flux, and AGE formation due to the hyperglycemia leads to renal lesions eventually [30]. Besides, it has been assumed that chronic hyperglycemia induces hemodynamic changes such as elevated mechanical tension and frictional forces to the glomeruli, and it contributes to renal injury by increased secretion of many pro-inflammatory cytokines and growth factors with further stimulation of the OS [63]. Therefore, Propolis's potential for glycemic control can help to prevent the initiation and progression of kidney disease (Fig. 2). 


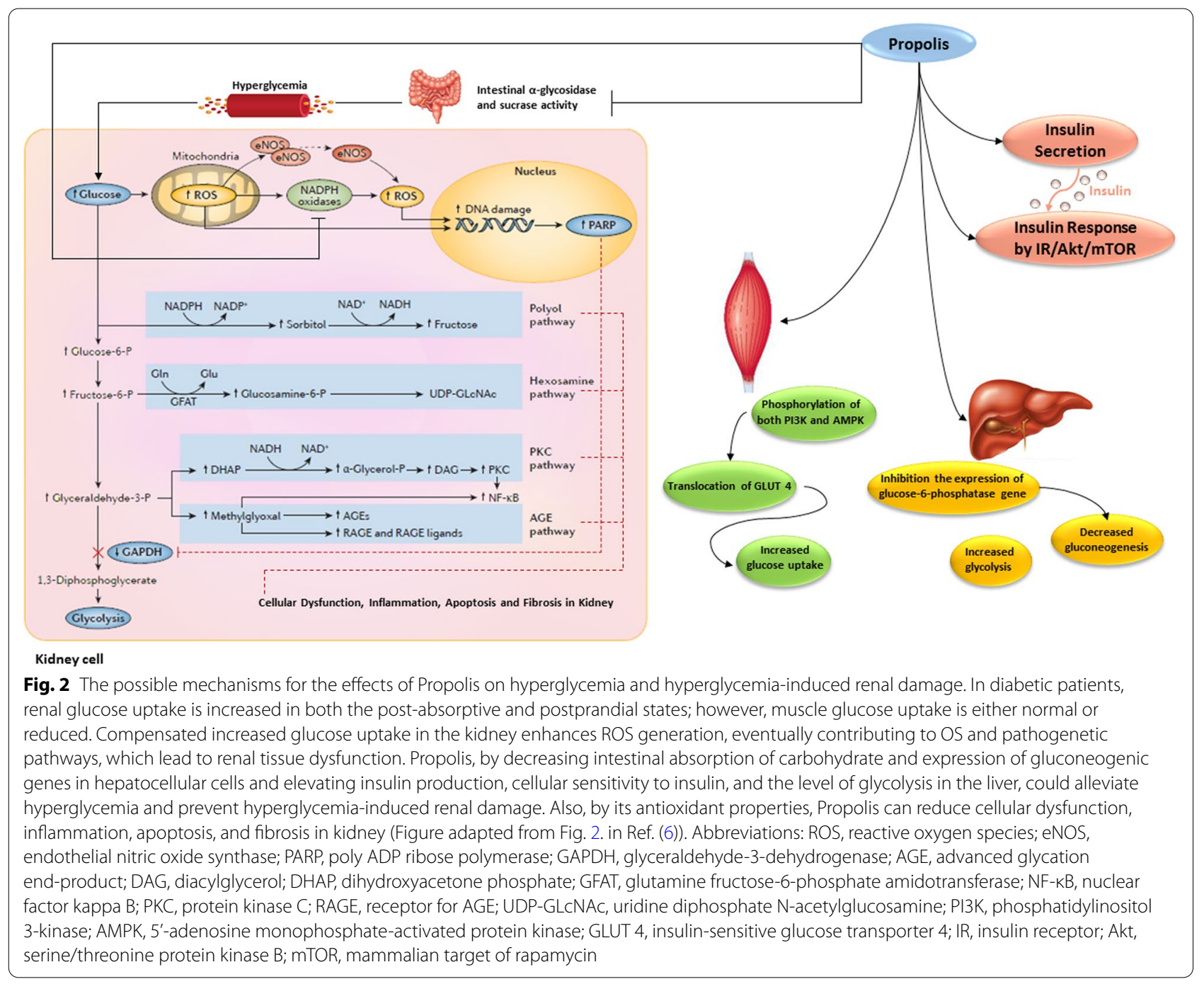

Dyslipidemia is one of the common features of kidney disease and a modifiable risk factor for CVD, the leading cause of mortality in AKI and CKD [6, 12, 69-71]. According to the studies reviewed here, five animal studies and two human ones assessed lipid profile in DN. The results on TC levels were controversial, with decreased levels in four studies [19, 21, 29, 31] and no significant changes in three studies [28, 32, 33]. Similarly, evidence regarding HDL-C levels was inconsistent; while the results of the four studies showed considerably increased levels of HDL-C $[19,21,31$, $32]$, there was not any significant increase in the other two $[29,33]$. Regarding TG levels, the results were controversial. Although there were decreased TG levels in all seven studies [19, 21, 28, 29, 31-33], significant changes were shown only in three articles $[19,21,31]$. Markedly, Propolis supplementation did not improve LDL-C concentrations, as it decreased in three studies
$[19,21,31]$ and did not show significant changes in the other three ones [29, 32, 33]. Moreover, the findings revealed that the effects of Propolis on VLDL-C were inconsistent [19, 21, 32]. The number of articles reporting RLP-C was not sufficient to make a judgment [33]. Dyslipidemia can stimulate OS and inflammation in the body, leading to vascular and renal injury [29, 32, 72]. On the other hand, kidney disease, regardless of the underlying cause, can result in dyslipidemia phenotype, which occurs in CKD patients, with this frequently observed pattern: increased TG, VLDL-C, intermediate-density lipoprotein (IDL), chylomicron remnants, and oxidized lipoproteins, decreased HDL-C, and various levels of serum TC and LDL-C concentrations [12, 71]. According to previous studies, Propolis may prevent or attenuate dyslipidemia by improving the glycemic status and relieving the OS [73-75]. In general, the possible lipid-lowering effects of Propolis are mediated 
by regulation of the lipid absorption, metabolism, accumulation, excretion, and synthesis in the body [74-76]. It is proposed that Propolis acts through up-regulation of the PPAR- $\gamma$ in the adipose tissue, which is a therapeutic target in DM, metabolic syndrome, and CVD, and involved in improving insulin sensitivity, inflammation, and dyslipidemia [57, 76, 77]. Moreover, Propolis can up-regulate the PPAR- $\alpha$ and PPAR- $\delta$, that control genes involved in lipid catabolism and freefatty acid $\beta$-oxidation, as well as down-regulate sterol regulatory element-binding protein-1 (SREBP-1) and consequently fatty acid synthase (FAS) and acetyl-CoA carboxylase $\alpha$ (ACAC- $\alpha)$, leading to decreased fatty acid synthesis in the liver $[57,74,76]$. Also, Propolis administration results in down-regulation of SREBP-2, 3-hydroxy-3-methylglutaryl-Coenzyme A synthase 1 (HMGCS-1), 3-hydroxy-3-methylglutaryl-Coenzyme A reductase (HMGCR), and squalene epoxidase (SQLE), leading to decreased hepatic cholesterol synthesis [57, 73, 74, 76]. Moreover, Propolis improves the lipoprotein lipase activity in the vessels (similar to lipid-lowering medications, such as fibrates) while inhibiting the hormone-sensitive lipase activity in adipose tissue, all leading to improved dyslipidemia [73, 75]. On the other hand, Propolis probably causes increased cholesterol $7 \alpha$-hydroxylase (CYP7A1) expression and leads to more neutral bile acid biosynthesis from cholesterol [74]. Besides, Propolis promotes protein expression of ATP-binding cassette transporters in the liver, which is related to reverse cholesterol transport and HDL-C formation [32]. In the gastrointestinal system, Propolis possibly inhibits the intestinal absorption of dietary lipids (TG and probably cholesterol) [76]. In addition, overweight/obesity is considered a significant risk factor for the development and severity of decreased GFR, regardless of the metabolic status [78, 79]. As Propolis could regulate the microbiota profile (both composition and function), leptin secretion, PPARs $(\alpha, \gamma$, and $\delta)$ action, and lipids metabolism (absorption, lipogenesis, and lipolysis), it can inhibit the weight gain and diminish the visceral adipose tissue accumulation [74, 8083]. For this reason, Propolis can also reduce the risk of CKD due to its anti-obesity properties [74, 80-83] (Fig. 3).

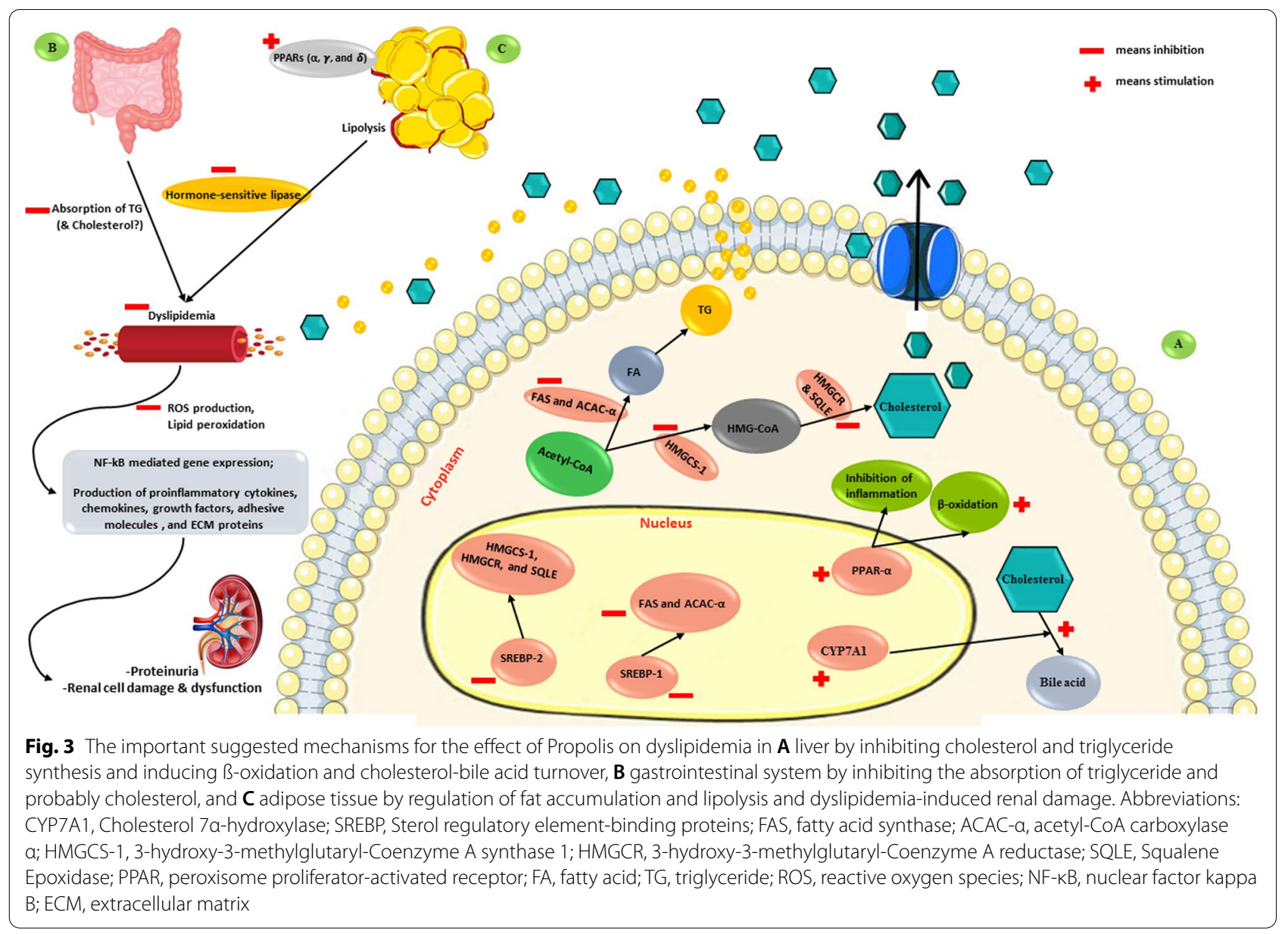


As mentioned earlier, OS is one of the leading risk factors for vascular and renal tissue dysfunction; therefore, the effect of Propolis on OS in kidney disease was evaluated in the current study. In a systematic review by Kocot et al. [15], it has been reported that Propolis as a natural agent can counteract the effects of OS, which is involved in the pathogenesis of various diseases. In this systematic review, Propolis supplementation found to be effective in decreasing the levels of MDA in serum [24, 26, 29-31], renal [22, 24, 25, 27-31], liver [28-30] and urine [27], and urinary levels of reactive oxygen metabolites (TBARS) [10], as lipid peroxidation indicators, significantly. Moreover, it had a potential effect on reducing the levels of renal tissue TOS [23] and OSI [23], and 8-OHdG formation [22], as a well-known biomarker of DNA damage in the renal tissue. Nitric oxide, as a reactive nitrogen species (RNS), is an important signaling biological molecule, and excessive NO can react with superoxide molecules producing strong oxidant peroxynitrite that is involved in the pathophysiology of ischemic AKI and DN [27, 30]. Nitric oxide is synthesized by a family of NO synthases (NOS), including neuronal NOS (nNOS), inducible NOS (iNOS), and endothelial NOS (eNOS). Nitric oxide-mediated effects can be beneficial or detrimental depending on the specific risk factors underlying the disease [84]. A reduction in the activity of eNOS is mainly responsible for the elevation of BP, renal impairment due to endothelial dysfunction, and OS [27, 84]. In contrast, abnormal expression of iNOS is likely to be related to the progression of vascular dysfunction, kidney damage, inflammation, and apoptosis. Inhibition of iNOS activity improves renal I/R damage, while eNOS has protective effects on I/R injury [27]. Endothelium-derived NO has an essential role in regulating angiogenesis and decreasing the interstitial fibrosis in the obstructed kidney. However, in rats with CKD, both eNOS and renal and vascular expression of iNOS decreased [84]. In this systematic review, two studies demonstrated a significant reduction in serum NOS without mentioning the type [29,30], and one study reported a significant increase in renal eNOS score after Propolis administration [27]. The results for serum NO showed insignificant reductions in two studies [29, 30] and a significant decrease in one study [26] following Propolis supplementation that there was not any clear conclusion about it. The effect of Propolis supplementation on the anti-oxidant biomarkers was also evaluated. The findings of these studies showed that Propolis supplementation had a potential role in increasing the levels of serum SOD [24, 26, 29, 30], serum GST [24, 26], liver GPx [29, 30], and renal GSH [22, 27, 31], CAT [29-31], FRAP [25], PON1 [23], HO-1 score [27], and TAS [23]. However, insufficient but also helpful results for serum CAT $[24,26,29,30]$ and renal $[22,25,29-31]$ and liver
$[29,30]$ SOD were observed. Nevertheless, Propolis supplementation had no significant effect on liver CAT [29, $30]$ and serum GPx [29, 30], and the results regarding renal GPx levels [25, 29, 30] were also controversial. Antioxidant properties of Propolis depend on the ingredients possessing phenolic characteristics such as phenolic acids and flavonoids, mainly due to their structure [15].

Inflammation is a crucial criterion for the development and progression of AKI and CKD [11, 24, 70, 85, 86]. In this systematic review, inflammatory markers were evaluated in kidney disease, showing a significant reduction in the levels of renal NF- $\mathrm{kB}$ [23], serum immunoglobulins [24], renal ED- $1^{+}$cells [10], and urinary MCP-1 [13] following Propolis supplementation; while IL- $1 \beta$ levels did not change significantly [32]. Notably, results on IL-6, TNF- $\alpha$, and hs-CRP were controversial. Serum and renal IL-6 levels decreased in one animal study after Propolis administration [24]; however, in two trials, serum IL-6 levels did not change significantly [32, 33]. Although serum levels of TNF- $\alpha$ decreased in all three human studies [22, 32, 33], these improvements in only two of them reached the level of significance [22,32]. Serum concentrations of hs-CRP were also assessed in two human studies; its levels declined in one study [32], with no change in another one [33]. More human studies are needed to determine the exact effects of Propolis on inflammation in patients with kidney disease. Oxidative stress-induced systemic and local renal inflammation develops as a cause and/or consequence of renal injury, hyperglycemia, or dyslipidemia $[1,11,12,70,72,87,88]$. It is shown that Propolis can potentially work as an anti-inflammatory agent in almost all inflammation stages due to the antioxidant and lipid-lowering effects of its flavonoids, especially CAPE, galangin, artepillin C, and quercetin $[14,42$, 57, 89-95]. Propolis exerts its effects through different mechanisms; the most important ones are inhibition of: expression and production of NF- $\mathrm{kB}$ and other signaling pathways (such as Toll-like receptor (TLR), JAK-STAT Protein kinase B (Akt), and lipopolysaccharide-induced signaling pathways), expression and activation of proinflammatory molecules (chemokines, prostanoids, growth factors, immunoglobulins, and cytokines), and expression and activation of iNOS $[14,23,90,91,93,96-$ 100]. As mentioned earlier, Propolis can also up-regulate PPAR- $\alpha$ and PPAR- $\gamma$; therefore, it may promote PPARsrelated anti-inflammatory and renoprotective effects [74, $76,77,101]$.

Results from eight animal studies showed that Propolis supplementation had potential effects on the prevention or restoration of renal tissue damages in kidney disease. The findings of three studies involving non-DM models of nephropathy showed that Propolis causes a lower slope in GS, tubular inflammation, tubular dilation 
and necrosis, renal congestion, renal hemorrhage, renal hydropic degeneration, and renal fibrosis [10, 22, 27]. Also, according to the results of five studies on DN, Propolis administration resulted in preserving the Bowman's capsules and decreasing vascular congestion, collapsed glomerular tuft, GS, the volume of the mesangial cells, GBM thickness, GA, vacuolization of the renal tubular epithelial cast, tubular dilation and atrophy, and interstitial inflammation and hemorrhage [24-26, 30]. However, in one study using the lowest dose, Propolis did not improve the corpuscular, tubular, and interstitial changes in diabetes models [28]. Moreover, evidence regarding the effects of Propolis on kidney weight was controversial; it decreased in three studies [19, 25, 31] but did not change in one another study [29]. The renal injury occurs because of metabolic and hemodynamic changes, mainly hyperglycemia, OS, inflammation, HTN, and dyslipidemia $[6,8,10,31,57,85,102-105]$. Regardless of the causes, kidney injury induces a repair process [85], however dysregulation of this process results in a vicious cycle of injury, leading to kidney maladaptation, dysfunction, scarring, and finally CKD [85]. This maladaptation advances the CKD progression in the way of occurring the cell activation, inflammation, fibrosis, tubuloglomerular feedback, and metabolic response (involving glomerular hyperfiltration, increased tubular activity, and hypoxia) $[85,106]$. Finally, as a direct consequence of CKD, a whole model of the progressive nephropathies happens: GS, increased production of matrix proteins, proliferation and hypertrophy of mesangial cells, tubulointerstitial proliferation, interstitial infiltration, inflammation and fibrosis, systemic and arterial HTN, impaired renal function, and proteinuria [6, 10, 85, 105, 107]. Besides, it should be noted that kidney weight, as another indicator for kidney morphology, changes in the early stages of kidney disease due to disturbed metabolism and increased tubular activity $[25,31]$.

The effect of Propolis supplementation on renal function was evaluated in several studies. Obtained results from the current systematic review revealed that Propolis administration might reduce UAE [24, 31], UAER $[29,30]$, and proteinuria [10, 13] significantly. Moreover, two studies reported remarkable increased serum total Protein $[19,26]$ and serum albumin [19, 21], which may indicate decreased proteinuria following supplementation with Propolis. Notably, six studies showed a significant reduction in $\mathrm{SCr}$ level due to Propolis supplementation [10,19, 21, 24, 27, 31], while no significant effects were reported in three other studies [29, 30, 32]. Besides, Propolis was found to be able to increase $\mathrm{ClCr}$ [27] and urinary $\mathrm{Cr}$ [24], but had no significant effects on CCR $[29,30]$, UACR $[13,33]$, and urine $\mathrm{pH}$ [33]. While Propolis supplementation did not significantly affect eGFR [13, 32, 33], in two clinical trials, it was decreased compared to the baseline in patients who took the placebo and not the Propolis $[32,33]$. Results regarding serum levels of uric acid, urea, and BUN were promising so that in three animal studies, serum levels of uric acid were decreased [19, $24,26]$, but no significant effects were observed in two clinical trials [32, 33]; despite the significant reduction of serum levels of urea in four studies [19, 21, 24, 27], one trial showed insignificant alterations [28]; in addition, BUN levels were significantly decreased in two of four studies [29, 31]. Results demonstrated a significant reduction in absolute excretion of $\mathrm{Na}^{+}$and $\mathrm{K}^{+}$as the markers of functional tubular viability and renal tubular injury [27] and a significant increase in serum $\mathrm{Na}^{+}$and $\mathrm{K}$ levels (restoration of $\mathrm{Na}^{+}$and $\mathrm{K}^{+}$levels to normal) after Propolis administration in one study [24], but no significant changes in another one [19]. The effect of Propolis on BP- as one of the leading causes of kidney disease- was also investigated. One study demonstrated a significant reduction in ADMA levels, which is likely to lead to endothelial dysfunction and increased in patients with HTN [23]. In another study, it was shown that although Propolis administration had no significant effect on $\mathrm{AII}^{+}$cells, it could significantly reduce systemic BP [10]. However, in a clinical trial conducted by Silveira et al. [13], following Propolis supplementation, the mean systolic and diastolic blood pressures remained stable during the follow-up period, without statistically significant between groups.

Taken together, mounting evidence indicated that supplementation with Propolis in kidney disease attenuated hyperglycemia, systemic and renal OS, systemic and glomerular BP, and leading to less kidney damage and proteinuria. In addition, the histological assessment showed that Propolis might be effective in renal lesions. Advanced renal injury may already be present even in newly diagnosed diabetic and non-diabetic nephropathies [108], and renal tissue improvement following Propolis intake may happens even before other metabolic alterations.

The renoprotective effects of Propolis is probably due to the presence of chrysin [93]. From this point of view, the current systematic review results showed that Propolis supplementation had potential effects on the restoration of renal tissue damages and renal function in AKI and CKD with different etiologies. However, the results were not sufficient to determine the effective dosage, duration of supplementation, and type of Propolis.

\section{Knowledge gaps and future directions}

Generally, due to the lack of human trials to understand the exact roles of Propolis in the management of kidney 
disease, prospective and well-designed studies with larger sample sizes and extended follow-up periods are needed to understand the underlying mechanisms. None of the reviewed studies measured blood concentrations of polyphenolic compounds of Propolis and didn't assess the effect of the administration route on bioavailability. Future clinical studies should be designed to compare the effect of geographical origins, seasons, and extraction methods.

\section{Conclusion}

Altogether, the current systematic review indicated that Propolis had potential effects on improving AKI and CKD by decreasing FBS, serum, liver, renal, and urine OS, proteinuria, and albuminuria, as well as renal tissue damages. However, the effects of Propolis on HbA1c, insulin, HOMA-IR, lipid profile (TC, TG, HDL-C, LDL$C$, and VLDL-C), NO, NOS, serum and renal IL-6, TNF$\alpha$, and hs-CRP, SCr, uric acid, urea, eGFR, BUN, BP, and kidney weight in subjects of AKI and CKD were satisfactory. Therefore, studies on the underlying mechanisms of the effectiveness of Propolis supplementation in patients with kidney disease are highly suggested.

\section{Abbreviations}

AKI: Acute kidney injury; CKD: Chronic kidney disease; GFR: Glomerular filtration rate; SCr: Serum creatinine; DM: Diabetes mellitus; HTN: Hypertension; DKD: Diabetic kidney disease; DN: Diabetic nephropathy; ESRD: End-stage renal disease; CVD: Cardiovascular disease; OS: Oxidative stress; PRISMA: Preferred reporting items for systematic reviews and meta-analyses; EEP: Ethanolic extracts of Propolis; HPLC: High-performance liquid chromatography; CAPE: Caffeic acid phenethyl ester; iNOS: Inducible nitric oxide synthase LD50: Median lethal dose; FBS: Fasting blood sugar; HOMA-IR: Homeostasis model assessment of insulin resistance; HOMA- $\beta$ : Homeostasis model assessment of $\beta$-cell function; QUICKI: Quantitative insulin sensitivity check index; CML: Carboxymethyl lysine; AGEs: Advanced glycation end products; $\mathrm{HbA} 1 \mathrm{C}$ Hemoglobin A1C; 2 hpp Glc: 2-Hour postprandial glucose; TC: Total cholesterol; TG: Triglyceride; LDL-C: Low-density lipoprotein cholesterol; VLDL-C: Very low-density lipoprotein cholesterol; HDL-C: High-density lipoprotein cholesterol; RLP-C: Remnant-like particle cholesterol; MDA: Malondialdehyde; CAT: Catalase; SOD: Superoxide dismutase; GST: Glutathione-S- transferase; NOS: Nitric oxide synthetase; GPx: Glutathione peroxidase; NO: Nitric oxide; //R: Ischemic-reperfusion; RP: Red Propolis; GSH: Glutathione; eNOS: Endothelial NOS; HO-1: Heme-oxygenase-1; TOS: Total oxidant status; OSI: Oxidative stress index; TAS: Total antioxidant status; PON1: Paraoxonase; 8-OHdG: 8-Hydroxy-2'deoxyguanosine; FRAP: Ferric-reducing ability of plasma; NF-kB: Nuclear factor kappa B; TNF-a: Tumor necrosis factor a; IL-6: Interleukin-6; MCP-1: Monocyte chemoattractant protein-1; hs-CRP: High sensitivity C-reactive protein; IL-1 $\beta$ : Interleukin-1 13; GS: Glomerulosclerosis; STZ: Streptozotocin; GBM: Glomerular basement membrane; GA: Glomerular area; \%GS: Percentage of GS; IG: GS index; WSDP: Water-soluble derivative of Propolis; UAE: Urinary albumin excretion; UAER: Urinary albumin excretion rate; CCR: Creatinine clearance rate; $\mathrm{ClCr}$ : Creatinine clearance; eGFR: Estimated GFR; UACR: Urinary albumin-to-creatinine ratio; ADMA: Asymmetric dimethylarginine; Cr: Creatinine; BP: Blood pressure; BUN: Blood urea nitrogen; GLUT: Insulin-sensitive glucose transporter; PI3K: Phosphatidylinositol 3-kinase; AMPK: 5'-Adenosine monophosphateactivated protein kinase; ROS: Reactive oxygen species; PKC: Protein kinase C; IDL: Intermediate-density lipoprotein; SREBP-1: Sterol regulatory elementbinding protein-1; FAS: Fatty acid synthase; ACAC-a: Acetyl-CoA carboxylase a; HMGCS-1: 3-Hydroxy-3-methylglutaryl-Coenzyme A synthase 1; HMGCR
: 3-Hydroxy-3-methylglutaryl-Coenzyme A reductase; SQLE: Squalene epoxidase; CYP7A1: Cholesterol 7a-hydroxylase; RNS: Reactive nitrogen species; nNOS: Neuronal NOS; TLR: Toll-like receptor; Akt: JAK-STAT protein kinase B.

\section{Supplementary Information}

The online version contains supplementary material available at https://doi. org/10.1186/s12986-021-00639-z.

Additional file 1. PRISMA 2020 Checklist.

\section{Acknowledgements}

This paper is derived from master's thesis of Tabriz University of Medical Sciences. We gratefully thank Dr. Vahid Maleki (Tabriz University of Medical Sciences) for his assistance in the literature search, study selection, and manuscript drafting.

\section{Authors' contributions}

$\mathrm{PA}, \mathrm{MA}, \mathrm{ZG}$, and $\mathrm{AO}$ carried out the concept and design of this study. PA, MA, and ZG conducted databases search, articles screening, and data extraction. PA, MA, and MRA prepared the primary manuscript. ZG, MRA, and AO critically apprised and revised the manuscript. All authors have contributed to the drafting of the manuscript and confirmed the last version of the document.

\section{Funding}

This research did not receive any specific grant from funding agencies in the public, commercial, or not-for-profit sectors.

\section{Availability of data and materials}

The datasets generated and analyzed during the current study are available from the corresponding author on reasonable request.

\section{Declarations}

Ethics approval and consent to participate

Not applicable.

\section{Consent for publication}

Not applicable.

\section{Competing interests}

The authors declare that they have no conflict of interest.

\section{Author details}

${ }^{1}$ Student Research Committee, School of Nutrition and Food Sciences, Tabriz University of Medical Sciences, Tabriz, Iran. ${ }^{2}$ Nutrition Research Center, Tabriz University of Medical Sciences, Tabriz, Iran. ${ }^{3}$ Department of Clinical Nutrition, School of Nutrition and Food Sciences, Tabriz University of Medical Sciences, Attar-Neishaburi St., Golgasht Alley, Azadi Blvd., Tabriz, Iran. ${ }^{4}$ Kidney Research Center, Tabriz University of Medical Sciences, Tabriz, Iran.

Received: 19 May 2021 Accepted: 21 December 2021

Published online: 20 January 2022

\section{References}

1. Gyurászová M, Gurecká R, Bábíčková J, Tóthová L.. Oxidative stress in the pathophysiology of kidney disease: implications for noninvasive monitoring and identification of biomarkers. Oxid Med Cell Longev. 2020. https://doi.org/10.1155/2020/5478708.

2. Levey $A S$, Becker $C$, Inker LA. Glomerular filtration rate and albuminuria for detection and staging of acute and chronic kidney disease in adults: a systematic review. JAMA. 2015;313(8):837-46.

3. Makris K, Spanou L. Acute kidney injury: definition, pathophysiology and clinical phenotypes. The clinical biochemist reviews. 2016;37(2):85. 
4. Hill NR, Fatoba ST, Oke JL, Hirst JA, O'Callaghan CA, Lasserson DS, et al. Global prevalence of chronic kidney disease-a systematic review and meta-analysis. PLoS ONE. 2016;11(7):e0158765.

5. Webster AC, Nagler EV, Morton RL, Masson P. Chronic kidney disease. The Lancet. 2017;389(10075):1238-52.

6. Thomas MC, Brownlee M, Susztak K, Sharma K, Jandeleit-Dahm KA, Zoungas $S$, et al. Diabetic kidney disease. Nat Rev Dis Primers. 2015;1(1):1-20.

7. Thomas MC, Cooper ME, Zimmet P. Changing epidemiology of type 2 diabetes mellitus and associated chronic kidney disease. Nat Rev Nephrol. 2016;12(2):73.

8. Toth-Manikowski S, Atta MG. Diabetic kidney disease: pathophysiology and therapeutic targets. J Diabetes Res. 2015. https://doi.org/10.1155/ 2015/697010.

9. Mills KT, Xu Y, Zhang W, Bundy JD, Chen C-S, Kelly TN, et al. A systematic analysis of worldwide population-based data on the global burden of chronic kidney disease in 2010. Kidney Int. 2015;88(5):950-7.

10. Teles F, da Silva TM, da Cruz Júnior FP, Honorato VH, de Oliveira CH, Barbosa APF, et al. Brazilian red propolis attenuates hypertension and renal damage in 5/6 renal ablation model. PLoS ONE. 2015;10(1):e0116535.

11. Akchurin M, Kaskel F. Update on inflammation in chronic kidney disease. Blood Purif. 2015;39(1-3):84-92.

12. Dincer N, Dagel T, Afsar B, Covic A, Ortiz A, Kanbay M. The effect of chronic kidney disease on lipid metabolism. Int Urol Nephrol. 2019;51(2):265-77.

13. Silveira MAD, Teles F, Berretta $A A$, Sanches TR, Rodrigues $C E$, Seguro $A C$, et al. Effects of Brazilian green propolis on proteinuria and renal function in patients with chronic kidney disease: a randomized, doubleblind, placebo-controlled trial. BMC Nephrol. 2019;20(1):140.

14. Braakhuis A. Evidence on the health benefits of supplemental propolis. Nutrients. 2019:11(11):2705.

15. Kocot J, Kiełczykowska M, Luchowska-Kocot D, Kurzepa J, Musik I. Antioxidant potential of propolis, bee pollen, and royal jelly: possible medical application. Oxidative Med Cell Longevity. 2018. https://doi. org/10.1155/2018/7074209.

16. Alvarez-Suarez JM. Bee products-chemical and biological properties. Berlin: Springer; 2017.

17. Pasupuleti VR, Sammugam L, Ramesh N, Gan SH. Honey, propolis, and royal jelly: a comprehensive review of their biological actions and health benefits. Oxid Med Cell Longev. 2017. https://doi.org/10.1155/ 2017/1259510.

18. Aminimoghadamfarouj $\mathrm{N}$, Nematollahi A. Propolis diterpenes as a remarkable bio-source for drug discovery development: a review. Int $J$ Mol Sci. 2017;18(6):1290

19. Laaroussi H, Bakour M, Ousaaid D, Aboulghazi A, Ferreira-Santos P, Genisheva Z, et al. Effect of antioxidant-rich propolis and bee pollen extracts against $\mathrm{D}$-glucose induced type 2 diabetes in rats. Food Res Int. 2020;138:109802-11.

20. El Adaouia Taleb R, Djebli N, Chenini H, Sahin H, Kolayli S. In vivo and in vitro anti-diabetic activity of ethanolic propolis extract. J Food Biochem. 2020;44:e13267.

21. El Menyiy N, Al-Wali N, El Ghouizi A, El-Guendouz S, Salom K, Lyoussi B. Potential therapeutic effect of Moroccan propolis in hyperglycemia, dyslipidemia, and hepatorenal dysfunction in diabetic rats. Iran J Basic Med Sci. 2019;22(11):1331.

22. Geyikoglu F, Koc K, Colak S, Erol HS, Cerig S, Yardimci BK, et al. Propolis and its combination with boric acid protect against ischemia/ reperfusion-induced acute kidney injury by inhibiting oxidative stress, inflammation, DNA damage, and apoptosis in rats. Biol Trace Elem Res. 2019:192(2):214-21.

23. Salmas RE, Gulhan MF, Durdagi S, Sahna E, Abdullah HI, Selamoglu Z. Effects of propolis, caffeic acid phenethyl ester, and pollen on renal injury in hypertensive rat: An experimental and theoretical approach. Cell Biochem Funct. 2017;35(6):304-14

24. El Rabey HA, Al-Seeni MN, Bakhashwain AS. The antidiabetic activity of Nigella sativa and propolis on streptozotocin-induced diabetes and diabetic nephropathy in male rats. Evid-Based Complement Alternat Med. 2017. https://doi.org/10.1155/2017/5439645.

25. Sameni HR, Ramhormozi P, Bandegi AR, Taherian AA, Mirmohammadkhani M, Safari M. Effects of ethanol extract of propolis on histopathological changes and anti-oxidant defense of kidney in a rat model for type 1 diabetes mellitus. J Diab Invest. 2016;7(4):506-13.

26. Jabir FA, Jabbar NK. Iraqi Propolis as antioxidant and protective therapy for kidney failure treatment of diabetic rats. Int J Pharm Tech Res. 2016;9:489-500.

27. da Costa MFB, Libório AB, Teles F, da Silva MC, Soares PMG, Meneses GC, et al. Red propolis ameliorates ischemic-reperfusion acute kidney injury. Phytomedicine. 2015;22(9):787-95.

28. Oršolić N, Sirovina D, Končić MZ, Lacković G, Gregorović G. Effect of Croatian propolis on diabetic nephropathy and liver toxicity in mice. BMC Complement Altern Med. 2012;12(1):117.

29. Zhu W, Chen M, Shou Q, Li Y, Hu F. Biological activities of Chinese propolis and Brazilian propolis on streptozotocin-induced type 1 diabetes mellitus in rats. Evid-Based Complement Alternat Med. 2011. https://doi.org/10.1093/ecam/neq025.

30. Zhu W, Li Y-H, Chen M-L, Hu F-L. Protective effects of Chinese and Brazilian propolis treatment against hepatorenal lesion in diabetic rats. Hum Exp Toxicol. 2011;30(9):1246-55.

31. Abo-Salem OM, El-Edel RH, Harisa G, El-Halawany N, Ghonaim MM. Experimental diabetic nephropathy can be prevented by propolis: effect on metabolic disturbances and renal oxidative parameters. Pak J Pharm Sci. 2009;22(2):205-10.

32. Zakerkish M, Jenabi M, Zaeemzadeh N, Hemmati AA, Neisi N. The effect of Iranian propolis on glucose metabolism, lipid profile, insulin resistance, renal function and inflammatory biomarkers in patients with type 2 diabetes mellitus: A randomized double-blind clinical trial. Sci Rep. 2019;9(1):1-11.

33. Fukuda T, Fukui M, Tanaka M, Senmaru T, I wase H, Yamazaki M, et al. Effect of Brazilian green propolis in patients with type 2 diabetes: A double-blind randomized placebo-controlled study. Biomed Rep. 2015;3(3):355-60.

34. Pandareesh M, Mythri R, Bharath MS. Bioavailability of dietary polyphenols: factors contributing to their clinical application in CNS diseases. Neurochem Int. 2015;89:198-208.

35. Weaver CM, Barnes S, Wyss JM, Kim H, Morré DM, Morré DJ, et al. Botanicals for age-related diseases: from field to practice. Am J Clin Nutr. 2008;87(2):493S-S497.

36. Alkhaldy A, Edwards CA, Combet E. The urinary phenolic acid profile varies between younger and older adults after a polyphenol-rich meal despite limited differences in in vitro colonic catabolism. Eur J Nutr. 2019;58(3):1095-111.

37. Yesiltas B, Capanoglu E, Firatligil-Durmus E, Sunay AE, Samanci T, Boyacioglu D. Investigating the in-vitro bioaccessibility of propolis and pollen using a simulated gastrointestinal digestion System. J Apic Res. 2014;53(1):101-8

38. Silva RB, Santos N, Martins N, Ferreira D, Barbosa F Jr, Souza VO, et al. Caffeic acid phenethyl ester protects against the dopaminergic neuronal loss induced by 6-hydroxydopamine in rats. Neuroscience. 2013;233:86-94.

39. Celli N, Dragani LK, Murzilli S, Pagliani T, Poggi A. In vitro and in vivo stability of caffeic acid phenethyl ester, a bioactive compound of propolis. J Agric Food Chem. 2007;55(9):3398-407.

40. Li B, Sedlacek M, Manoharan I, Boopathy R, Duysen EG, Masson P, et al. Butyrylcholinesterase, paraoxonase, and albumin esterase, but not carboxylesterase, are present in human plasma. Biochem Pharmacol. 2005;70(11):1673-84.

41. Vauzour D. Dietary polyphenols as modulators of brain functions: biological actions and molecular mechanisms underpinning their beneficial effects. Oxid Med Cell Longev. 2012. https://doi.org/10.1155/ 2012/914273.

42. Anjum SI, Ullah A, Khan KA, Attaullah M, Khan H, Ali H, et al. Composition and functional properties of propolis (bee glue): A review. Saudi J Biol Sci. 2019;26(7):1695-703.

43. Cornara L, Biagi M, Xiao J, Burlando B. Therapeutic properties of bioactive compounds from different honeybee products. Front Pharmacol. 2017:8:412

44. Bazmandegan G, Boroushaki MT, Shamsizadeh A, Ayoobi F, Hakimizadeh E, Allahtavakoli M. Brown propolis attenuates cerebral ischemiainduced oxidative damage via affecting antioxidant enzyme system in mice. Biomed Pharmacother. 2017;85:503-10. 
45. Cao G, Ying P, Yan B, Xue W, Li K, Shi A, et al. Pharmacokinetics, safety, and tolerability of single and multiple-doses of pinocembrin injection administered intravenously in healthy subjects. J Ethnopharmacol. 2015;168:31-6.

46. Li Y-J, Lin J-L, Yang C-W, Yu C-C. Acute renal failure induced by a Brazilian variety of propolis. Am J Kidney Dis. 2005;46(6):e125-9.

47. Wagh VD. Propolis: a wonder bees product and its pharmacological potentials. Adv Pharmacol Sci. 2013. https://doi.org/10.1155/2013/ 308249.

48. Arvouet-Grand A, Lejeune B, Bastide P, Pourrat A, Privat A, Legret P. Propolis extract. I. Acute toxicity and determination of acute primary cutaneous irritation index. J Pharm Belg. 1993;48(3):165-70.

49. Hamza RZ, Diab A, Abd E-A. Hyperglycemic effect of chlorpyrifos, profenofos and possible ameliorative role of propolis and ginseng. Sci Agric. 2014;1:9-14.

50. Hsu C-Y, Chiang W-C, Weng T-I, Chen W-J, Yuan A. Laryngeal edema and anaphalactic shock after topical propolis use for acute pharyngitis. Am J Emerg Med. 2004;22(5):432-3.

51. Hay K, Greig D. Propolis allergy: a cause of oral mucositis with ulceration. Oral Surg Oral Med Oral Pathol. 1990;70(5):584-6.

52. Walgrave SE, Warshaw EM, Glesne LA. Allergic contact dermatitis from propolis. Dermatitis. 2005;16(4):209-15.

53. Rudzki E, Grzywa Z, Pomorski Z. New data on dermatitis from propolis. Contact Dermatitis. 1985;13(3):198-9.

54. Hausen B, Wollenweber E, Senff H, Post B. Propolis allergy: (I). Origin, properties, usage and literature review. Contact Dermatitis. 1987;17(3):163-70.

55. Rudzki E, Grzywa Z. Dermatitis from propolis. Contact Dermatitis. 1983;9(1):40-5.

56. Karimian J, Hadi A, Pourmasoumi M, Najafgholizadeh A, Ghavami A. The efficacy of Propolis on markers of glycemic control in adults with type 2 diabetes mellitus: A systematic review and meta-analysis. Phytother Res. 2019;33(6):1616-26.

57. Kitamura $\mathrm{H}$. Effects of Propolis extract and propolis-derived compounds on obesity and diabetes: knowledge from cellular and animal models. Molecules. 2019;24(23):4394.

58. Mujica V, Orrego R, Pérez J, Romero P, Ovalle P, Zúñiga-Hernández J, et al. The role of propolis in oxidative stress and lipid metabolism: a randomized controlled trial. Evid-Based Complement Alternat Med. 2017. https://doi.org/10.1155/2017/4272940.

59. Zhang H, Wang G, Dong J. Inhibitory properties of aqueous ethanol extracts of Propolis on alpha-glucosidase. Evid-Based Complement Alternat Med. 2015. https://doi.org/10.1155/2015/587383.

60. Matsui T, Ebuchi S, Fujise T, Abesundara KJ, Doi S, Yamada H, et al. Strong antihyperglycemic effects of water-soluble fraction of Brazilian propolis and its bioactive constituent, 3, 4, 5-tri-O-caffeoylquinic acid. Biol Pharma Bull. 2004;27(11):1797-803.

61. Ueda M, Hayashibara K, Ashida H. Propolis extract promotes translocation of glucose transporter 4 and glucose uptake through both PI3K-and AMPK-dependent pathways in skeletal muscle. BioFactors. 2013;39(4):457-66.

62. Kang LJ, Lee HB, Bae HJ, Lee SG. Antidiabetic effect of propolis: reduction of expression of glucose-6-phosphatase through inhibition of Y279 and Y216 autophosphorylation of GSK-3a/ $\beta$ in HepG2 cells. Phytother Res. 2010;24(10):1554-61.

63. Jha JC, Ho F, Dan C, Jandeleit-Dahm K. A causal link between oxidative stress and inflammation in cardiovascular and renal complications of diabetes. Clin Sci. 2018;132(16):1811-36.

64. Amorim RG, Guedes GDS, Vasconcelos SML, Santos JCDF. Kidney disease in diabetes mellitus: cross-linking between hyperglycemia, redox imbalance and inflammation. Arq Bras Cardiol. 2019;112(5):577-87.

65. Gerich JE. Role of the kidney in normal glucose homeostasis and in the hyperglycaemia of diabetes mellitus: therapeutic implications. Diabet Med. 2010;27(2):136-42.

66. Meyer C, Woerle HJ, Dostou JM, Welle SL, Gerich JE. Abnormal renal, hepatic, and muscle glucose metabolism following glucose ingestion in type 2 diabetes. Am J Physiol-Endocrinol Metab. 2004;287(6):E1049-56

67. Meyer C, Stumvoll M, Nadkarni V, Dostou J, Mitrakou A, Gerich J. Abnormal renal and hepatic glucose metabolism in type 2 diabetes mellitus. J Clin Investig. 1998;102(3):619-24.
68. Chowdhury S, Ghosh S, Das AK, Sil PC. Ferulic acid protects hyperglycemia-induced kidney damage by regulating oxidative insult, inflammation and autophagy. Front Pharmacol. 2019;10:27.

69. Kennard A, Singer R. Lipid lowering in renal disease. Aust Prescr. 2017;40(4):141.

70. Cachofeiro V, Goicochea M, De Vinuesa SG, Oubiña P, Lahera V, Luño J. Oxidative stress and inflammation, a link between chronic kidney disease and cardiovascular disease: New strategies to prevent cardiovascular risk in chronic kidney disease. Kidney Int. 2008;74:S4-9.

71. Vaziri ND. Role of dyslipidemia in impairment of energy metabolism, oxidative stress, inflammation and cardiovascular disease in chronic kidney disease. Clin Exp Nephrol. 2014;18(2):265-8.

72. Zhang C, Wang K, Yang L, Liu R, Chu Y, Qin X, et al. Lipid metabolism in inflammation-related diseases. Analyst. 2018;143(19):4526-36.

73. Zarzecki MS, Araujo SM, Bortolotto VC, de Paula MT, Jesse CR, Prigol M. Hypolipidemic action of chrysin on Triton WR-1339-induced hyperlipidemia in female C57BL/6 mice. Toxicol Rep. 2014;1:200-8.

74. Koya-Miyata S, Arai N, Mizote A, Taniguchi Y, Ushio S, Iwaki K, et al. Propolis prevents diet-induced hyperlipidemia and mitigates weight gain in diet-induced obesity in mice. Biol Pharm Bull. 2009;32(12):2022-8.

75. Oršolić N, Landeka Jurčević I, Đikić D, Rogić D, Odeh D, Balta V, et al. Effect of propolis on diet-induced hyperlipidemia and atherogenic indices in mice. Antioxidants. 2019;8(6):156.

76. Ichi I, Hori H, Takashima Y, Adachi N, Kataoka R, Okihara K, et al. The beneficial effect of propolis on fat accumulation and lipid metabolism in rats fed a high-fat diet. J Food Sci. 2009;74(5):H127-31.

77. lio A, Ohguchi K, Inoue H, Maruyama H, Araki Y, Nozawa Y, et al. Ethanolic extracts of Brazilian red propolis promote adipocyte differentiation through PPARY activation. Phytomedicine. 2010;17(12):974-9.

78. Qiu Y, Zhao Q, Gu Y, Wang N, Yu Y, Wang R, et al. Association of metabolic syndrome and its components with decreased estimated glomerular filtration rate in adults. Ann Nutr Metab. 2019;75(3):168-78.

79. Alizadeh S, Esmaeili H, Alizadeh M, Daneshzad E, Sharifi L, Radfar H, et al. Metabolic phenotypes of obese, overweight, and normal weight individuals and risk of chronic kidney disease: a systematic review and meta-analysis. Arch Endocrinol Metab. 2019;63:427-37.

80. Zulhendri F, Ravalia M, Kripal K, Chandrasekaran K, Fearnley J, Perera CO. Propolis in metabolic syndrome and its associated chronic diseases: A narrative review. Antioxidants. 2021;10(3):348.

81. Zheng Y, Wu Y, Tao L, Chen X, Jones TJ, Wang K, et al. Chinese Propolis prevents obesity and metabolism syndromes induced by a high fat diet and accompanied by an altered gut microbiota structure in mice. Nutrients. 2020;12(4):959.

82. Rivera-Yañez N, Rivera-Yañez CR, Pozo-Molina G, Méndez-Catalá CF, Méndez-Cruz AR, Nieto-Yañez O. Biomedical properties of propolis on diverse chronic diseases and its potential applications and health benefits. Nutrients. 2021;13(1):78.

83. Cai W, Xu J, Li G, Liu T, Guo X, Wang H, et al. Ethanol extract of propolis prevents high-fat diet-induced insulin resistance and obesity in association with modulation of gut microbiota in mice. Food Res Int. 2020;130:108939.

84. Lee J, Bae EH, Ma SK, Kim SW. Altered nitric oxide system in cardiovascular and renal diseases. Chonnam Med J. 2016;52(2):81.

85. Schnaper HW. The tubulointerstitial pathophysiology of progressive kidney disease. Adv Chronic Kidney Dis. 2017;24(2):107-16.

86. Sharain K, Hoppensteadt D, Bansal V, Singh A, Fareed J. Progressive increase of inflammatory biomarkers in chronic kidney disease and end-stage renal disease. Clin Appl Thromb Hemost. 2013;19(3):303-8.

87. Himmelfarb J. Relevance of oxidative pathways in the pathophysiology of chronic kidney disease. Cardiol Clin. 2005;23(3):319-30.

88. Yaribeygi H, Farrokhi FR, Rezaee R, Sahebkar A. Oxidative stress induces renal failure: A review of possible molecular pathways. J Cell Biochem. 2018;119(4):2990-8.

89. Viuda-Martos M, Ruiz-Navajas Y, Fernández-López J, Pérez-Álvarez J. Functional properties of honey, propolis, and royal jelly. J Food Sci. 2008;73(9):R117-24

90. Araujo MA, Libério SA, Guerra RN, Ribeiro MNS, Nascimento FR. Mechanisms of action underlying the anti-inflammatory and immunomodulatory effects of propolis: a brief review. Rev Bras. 2012;22(1):208-19.

91. Sforcin JM. Biological properties and therapeutic applications of propolis. Phytother Res. 2016;30(6):894-905. 
92. Santos LM, Fonseca MS, Sokolonski AR, Deegan KR, Araújo RP, Umsza-Guez MA, et al. Propolis: types, composition, biological activities, and veterinary product patent prospecting. J Sci Food Agric. 2020;100(4):1369-82.

93. Ahad A, Ganai AA, Mujeeb M, Siddiqui WA. Chrysin, an anti-inflammatory molecule, abrogates renal dysfunction in type 2 diabetic rats. Toxicol Appl Pharmacol. 2014;279(1):1-7.

94. Mani R, Natesan V. Chrysin: Sources, beneficial pharmacological activities, and molecular mechanism of action. Phytochemistry. 2018;145:187-96.

95. Akyol S, Ugurcu V, Altuntas A, Hasgul R, Cakmak O, Akyol O. Caffeic acid phenethyl ester as a protective agent against nephrotoxicity and/ or oxidative kidney damage: a detailed systematic review. Sci World J. 2014. https://doi.org/10.1155/2014/561971.

96. Freires IA, de Alencar SM, Rosalen PL. A pharmacological perspective on the use of Brazilian Red Propolis and its isolated compounds against human diseases. Eur J Med Chem. 2016;110:267-79.

97. Farooqui T, Farooqui A. Molecular mechanism underlying the therapeutic activities of propolis: a critical review. Curr Nutr Food Sci. 2010;6(3):186-99.

98. Ramos A, Miranda JD. Propolis: a review of its anti-inflammatory and healing actions. J Venomous Anim Toxins Include Trop Dis. 2007;13(4):697-710

99. Bueno-Silva B, Kawamoto D, Ando-Suguimoto ES, Alencar SM, Rosalen PL, Mayer MP. Brazilian red propolis attenuates inflammatory signaling cascade in LPS-activated macrophages. PLOS ONE. 2015;10(12):e0144954.

100. Murtaza G, Sajjad A, Mehmood Z, Shah SH, Siddiqi AR. Possible molecular targets for therapeutic applications of caffeic acid phenethyl ester in inflammation and cancer. J Food Drug Anal. 2015;23(1):11-8.

101. Chung S, Park CW. Role of peroxisome proliferator-activated receptor a in diabetic nephropathy. Diabetes Metab J. 2011;35(4):327-36.

102. Yamagishi S-I, Imaizumi T. Diabetic vascular complications: pathophysiology, biochemical basis and potential therapeutic strategy. Curr Pharma Des. 2005;11(18):2279-99.

103. Shah SV, Baliga R, Rajapurkar M, Fonseca VA. Oxidants in chronic kidney disease. J Am Soc Nephrol. 2007;18(1):16-28.

104. Badal SS, Danesh FR. New insights into molecular mechanisms of diabetic kidney disease. Am J Kidney Dis. 2014;63(2):S63-83.

105. Gonçalves ARR, Fujihara CK, Mattar AL, Malheiros DMAC, Noronha IL, De Nucci G, et al. Renal expression of COX-2, ANG II, and AT1 receptor in remnant kidney: strong renoprotection by therapy with losartan and a nonsteroidal anti-inflammatory. Am J Physiol-Renal Physiol. 2004;286(5):F945-54.

106. Mason RM, Wahab NA. Extracellular matrix metabolism in diabetic nephropathy. J Am Soc Nephrol. 2003;14(5):1358-73.

107. Arias SCA, Valente CP, Machado FG, Fanelli C, Origassa CST, de Brito T, et al. Regression of albuminuria and hypertension and arrest of severe renal injury by a losartan-hydrochlorothiazide association in a model of very advanced nephropathy. PLoS ONE. 2013;8(2):e56215.

108. Teles F, Machado FG, Ventura BH, Malheiros DM, Fujihara CK, Silva $L F$, et al. Regression of glomerular injury by losartan in experimental diabetic nephropathy. Kidney Int. 2009;75(1):72-9.

\section{Publisher's Note}

Springer Nature remains neutral with regard to jurisdictional claims in published maps and institutional affiliations.

Ready to submit your research? Choose BMC and benefit from:

- fast, convenient online submission

- thorough peer review by experienced researchers in your field

- rapid publication on acceptance

- support for research data, including large and complex data types

- gold Open Access which fosters wider collaboration and increased citations

- maximum visibility for your research: over $100 \mathrm{M}$ website views per year

At BMC, research is always in progress.

Learn more biomedcentral.com/submissions 